\title{
A Social-Ecological Systems Understanding of Drivers of Degradation in the Tsitsa River Catchment to Inform Sustainable Land Management
}

\author{
Adela Itzkin ${ }^{1, * \mathbb{D}}$, Mary C. Scholes ${ }^{1}\left(\mathbb{D}\right.$, Jai Kumar Clifford-Holmes ${ }^{2} \mathbb{D}$, Kate Rowntree ${ }^{3}$, Bennie van der Waal ${ }^{3}$ \\ and Kaera Coetzer ${ }^{4}$ \\ 1 School of Animal, Plant and Environmental Sciences (APES), University of Witwatersrand, \\ Johannesburg 2000, South Africa; mary.scholes@wits.ac.za \\ 2 Institute for Water Research (IWR), Rhodes University, Makhanda 6139, South Africa; \\ jai.clifford.holmes@gmail.com \\ 3 Geography Department, Rhodes University, Makhanda 6139, South Africa; k.rowntree@ru.ac.za (K.R.); \\ bvdwaal@gmail.com (B.v.d.W.) \\ 4 Global Change Institute, University of Witwatersrand, Johannesburg 2000, South Africa; klcoetzer@gmail.com \\ * Correspondence: adelaitzkin@gmail.com; Tel.: +27-11-7176407
}

check for

updates

Citation: Itzkin, A.; Scholes, M.C.; Clifford-Holmes, J.K.; Rowntree, K.; van der Waal, B.; Coetzer, K. A Social-Ecological Systems Understanding of Drivers of Degradation in the Tsitsa River Catchment to Inform Sustainable Land Management. Sustainability 2021, 13, 516. https://doi.org/ $10.3390 /$ su13020516

Received: 9 December 2020 Accepted: 31 December 2020 Published: 7 January 2021

Publisher's Note: MDPI stays neutral with regard to jurisdictional clai$\mathrm{ms}$ in published maps and institutional affiliations.

Copyright: (C) 2021 by the authors. Licensee MDPI, Basel, Switzerland. This article is an open access article distributed under the terms and conditions of the Creative Commons Attribution (CC BY) license (https:// creativecommons.org/licenses/by/ $4.0 /)$.

\begin{abstract}
Understanding the interactions of the social and biophysical drivers of land degradation is crucial for developing adaptive management actions for future sustainability. A research-praxis project, the 'Tsitsa Project' (TP), applies a social-ecological systems (SES) approach where researchers, natural resource managers, and residents collaborate to support sustainable livelihoods and improved natural resource management for the degraded Tsitsa River Catchment (TRC) in South Africa. A system diagramming approach was coupled with findings from interviews, workshops, literature, and two conceptual frameworks. Data inputs were qualitatively integrated to provide a systemic snapshot of how the context-specific social and biophysical drivers are interlinked and how they interact, revealing multiple processes that operate simultaneously to cause and exacerbate land degradation. Physical and climatic variables, changes in land use and cover, and overgrazing were identified as key factors leading to degradation. Additionally, poverty and disempowerment were also important. While little can be done to influence the physical aspects (steep topography and duplex soils) and climatic variables (extreme rainfall and drought), carefully planned changes in land use and management could produce dual-benefits for improving landscape conditions and sustainable livelihoods. This analysis will inform integrated planning processes to monitor, avoid, reduce and reverse land degradation.
\end{abstract}

Keywords: land degradation; social-ecological systems; systems thinking; sustainable land management

\section{Introduction}

Social-ecological systems (SESs) are characterized by complexity, high connectivity, and the presence of positive and negative feedback loops involving social and biophysical variables which can have desirable or undesirable outcomes [1,2]. Land degradation is a process with undesirable social and ecological outcomes that can be especially devastating for the world's poorest people living in dryland areas. Land degradation is classified into soil degradation and vegetation degradation, both of which are important and often interrelated [3]. The definition of land degradation traditionally focused on the biophysical aspects (i.e., vegetation change and soil loss), but has more recently been framed as a social-ecological phenomenon resulting in "the reduction in the capacity of the land to provide ecosystem goods and services, over a period of time, for its beneficiaries" [4] (p. 7). The major factors leading to land degradation globally are land use changes and unsustainable land management practices; changes in land use and management are often driven by system shocks (abrupt change), trends (long-term changes), or seasonality 
(short-term variability) [5]. Addressing issues around land degradation is fundamental to achieving the Sustainable Development Goal (SDG) target 15.3, "to combat desertification, restore degraded land and soil, including land affected by desertification, drought, and floods, and strive to achieve a land degradation-neutral world" by 2030 [6]. A systemic approach to land degradation can also support other SDGs related to climate change, poverty eradication, food security, environmental protection, and the sustainable use of natural resources $[7,8]$. In recognition of the urgent need to restore degraded ecosystems, 2021-2030 has been declared the UN Decade on Ecosystem Restoration with the mission of preventing, halting, and reversing the degradation of ecosystems worldwide [8].

Land degradation is one of South Africa's most critical environmental issues $[9,10]$ and negatively impacts the livelihoods of the rural communities [11]. Land degradation decreases the provision of ecosystem services crucial to enable rural communities to fulfill their (physiological, psychological, and social) needs [12]. The drivers of land degradation are the fundamental forces causing the degradation of the coupled social-ecological system (e.g., climate change, policies, and physical aspects). Understanding both the social and biophysical drivers, and the way that they interact to place pressure on the landscape, changing its condition, is crucial to develop adaptive management measures that will alter current trends towards more desirable and sustainable outcomes $[7,13]$.

While context-dependency is a key determinant of the land degradation impacts of drivers, the nature of an environmental problem in any given case is not entirely unique [14]. Instead, it reflects a series of core challenges that occur repeatedly across many different cases and contexts. In the case of South Africa, high levels of land degradation are associated with both biophysical and socio-economic factors that are apparent throughout the country's rural landscapes [3]. Many land degradation outcomes in South Africa can be traced back to the historical land tenure policies of the country where the formation of homelands led to over-crowding [15]. Colonial and Apartheid policies controlling where people could live, work, and school also contributed to the entrenchment of poverty and disempowerment in the former homelands, which reduced the capacity of households to develop alternative livelihood coping strategies, and contributed to continued degradation [16].

Yet while case studies of environmental problems like land degradation share some global, regional, or national 'core challenges', each has its own history, rooted in its own specific social and ecological context that must be taken into consideration for sustainable and effective management. Case studies are valuable because they allow researchers to gather complementary quantitative data and rich qualitative data that helps to contextualize the study and to infer causality [14]. The Tsitsa River Catchment (TRC) is such a case study. It is home to a unique, ongoing research-praxis project, the Tsitsa Project (TP, formerly the Ntabelanga-Laleni Ecological Infrastructure Project), which began in 2014 and is the South African Government's flagship restoration project [17]. The TP has an explicit SES framing that is based on applied transdisciplinary research (in the space between implementation and academic research) to improve the landscape and sustainable livelihoods of the degraded, rural TRC. The TP aims to improve social and ecological sustainability using an SES approach that combines knowledge and expertise from social and natural sciences, practitioners, and communities. The TP has put effort into building trust with and the capacity within the communities, foremost through several years of continued participatory engagement and the employment of community members to participate in social and biophysical monitoring activities [18]. Adaptive management in a degraded SES like the TRC requires an understanding of the key social and biophysical drivers of degradation for that system. The TP recognizes that taking social-ecological drivers of degradation into account is crucial to the project's chances of success [19].

This paper will provide a synthesis of the drivers of degradation in the TRC case study through an integrated SES approach. This is a unique case study and approach in the South African context that adds value to our understanding of the drivers of land degradation by integrating transdisciplinary perspectives that can be used to identify potential leverage 
points for adaptive management interventions. The TP's social-biophysical approach to understanding the environmental, social, economic, and governance factors which drive the system, and importantly the particular linkages between them, provides an opening to conduct 'degradation research' in novel ways, such as through systems thinking. Defined as "a set of synergistic analytic skills used to improve the capability of identifying and understanding systems, predicting their behaviors, and devising modifications to them in order to produce desired effects" [20] (p. 7), systems thinking consists of three kinds of things: elements (in this case, the drivers, pressures and stressors and responses that affect the condition of the TRC), interconnections (the way these characteristics relate to and/or feed back into each other), and a function or purpose (in this case, to systemically understand land degradation to inform sustainable land management of the TRC). Since real-world phenomena are typically not explained through a single, clear, unidirectional path linking a cause to an effect, systems diagramming drawing on data about the drivers of degradation gathered from within the TP will elucidate some key ways that the contextspecific drivers interact to result in multiple processes that operate simultaneously to cause and exacerbate the land degradation in the TRC. The paper will then make a theoretical case for the use of a system's application of Drivers-Pressure-Stressors-Condition-Responses $\left(\mathrm{DPSCR}_{4}\right)$ and Land Degradation Neutrality (LDN) frameworks with regards to better degradation intervention outcomes.

\subsection{The Study Area: The Tsitsa River Catchment}

The Tsitsa River Catchment (focus area of 200,000 ha, as per Figure 1) lies in the Eastern Cape province of South Africa. The catchment is considered sub-humid and is characterized by areas of steep topography [21,22]. Soils are generally erodible, especially in the lower catchment, as seen by the formation of extensive gullies $[23,24]$. The catchment is comprised of two types of rural landholdings (private and communal) with similar ownership patterns as under the pre-1994 Apartheid regime [25]. The communal land, where the majority of the catchment's population resides, is found mostly in the middle and lower parts of the catchment, which coincides with more erodible soils [25]. Historically, Apartheid policies and actions (including the political and administrative separation of the Transkei homeland from the Republic of South Africa, laws restricting black ownership of land, urban labor controls, limited investment in education, social grants, and betterment) impacted the social-ecological landscape of the TRC, increasing disempowerment and poverty, and changing land use and land cover patterns [16].

The ultimate aim of the TP research is twofold. Firstly, to provide and synthesize relevant scientific and local knowledge to evaluate the natural and social capital of the TRC, with regards to whether it is or is not progressing toward desired long-term goals. Secondly, to link this understanding to management and implementation processes needed to achieve sustainability of the TRC. Land degradation in the Tsitsa catchment can be seen through the dissection by deeply incised gullies ('dongas'), the loss of grassy vegetation cover and associated soil erosion and loss of soil fertility, as well as encroachment of degraded grasslands by woody vegetation (largely by invasive alien plants) [25]. These processes reduce the productivity of the land, making it less able to support the people who live on it. The complex SES framing of the TP has a strong focus on livelihoods and governance in the area because through livelihoods people benefit and through good governance the SES can be sustained. This is a departure from the South African Department of the Environment, Forestry and Fisheries' (DEFF) business-as-usual management activities to counter land degradation by reducing soil loss through restoring degraded ecological infrastructure, with limited investment in long-term livelihood benefits and governance institutions that support sustainability. The TP's singular nature as a research-praxis project (with praxis being the interaction between research and practice), funded by DEFF who are using it as an experimental space to inform their own processes and projects, provides exciting learning opportunities that can be extended to other projects interested in using a similar approach. 


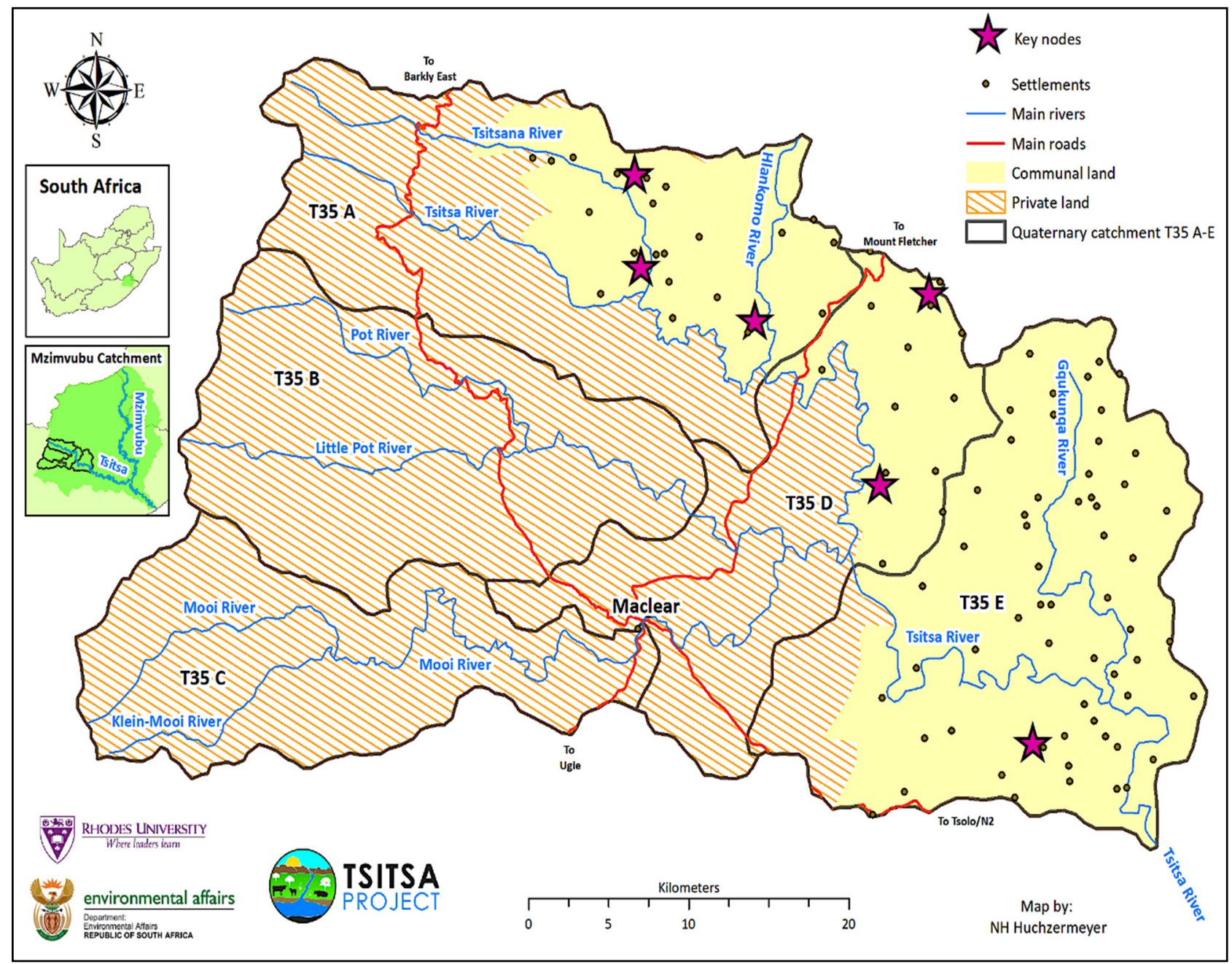

Figure 1. Map of the Tsitsa River Catchment. Quaternary catchments are hydrological delineations of sub-catchments (numbered by the South African system of T35A-E); and key nodes refer to focal areas for the Tsitsa Project's engaged research and restoration work. Map by N.H. Huchzermeyer.

A desktop review of key documents from the Tsitsa Project $[19,25-28]$ and the responses at a workshop with the heads of all the TP research-praxis communities of practice (CoPs) as well as various key stakeholder organizations, held in May 2020, highlighted the need for a synthesis of the drivers of degradation in this system. Such a systemic synthesis would help build a common understanding of the problem context, which is important for the identification of suitable (effective and sustainable) leverage points and interventions that address the drivers of degradation rather than the symptoms. The synthesis builds on an earlier review of the environmental, social, and historic processes contributing to degradation provided through the Water Research Commission funded "Green Village Project" [16].

\subsection{Framework}

One of the ways to explore the interactions between society and the environment and their consequences is the use of frameworks for assessing ecosystem health. Ecological health assessment frameworks have followed two main approaches. The first one is derived from concepts within stress ecology, ecological risk assessments, and ecological indicators [29]. These frameworks are closely related to hypothesis-driven scientific studies on causal relationships between environmental stressors (whether natural or anthropogenic) and their effect on ecosystems and their components [29]. The second approach is focused on environmental-management, based on the Pressure-State-Response (PSR) framework 
and its derivative, the Driver-Pressure-State-Impact-Response (DPSIR) framework [30]. First developed as part of the European Environment Agency Programme, DPSIR has been adopted as an analytical framework by UNEP and has been applied to various environmental studies in Europe [30-32]. A strength of the DPSIR framework is that it considers humans an integral part of the system generating pressures, sensing the impact, and applying responses [33]. A deficiency of DPSIR, according to Harwell and others [29], is that in distinguishing between impacts and state, it implies that there exists some baseline or 'natural state' for an ecosystem and that impacts constitute some deviation from that state. Human interactions are thus positioned only as adverse without accounting for positive contributions.

The Drivers-Pressure-Stressors-Condition-Responses (DPSCR 4 ) is a derivative of the DPSIR framework, which replaces 'Impact' with 'Condition', where condition describes the state of the environment (in terms of ecological health, ecosystem services, and human well-being) and four types of responses are identified: reduction of stressor sources, remediation of existing stressors, ecological restoration, and ecological recovery [29]. Researchers from the TP have used the DPSCR 4 as an integrated monitoring framework [24]. The TP defines 'drivers' as the fundamental forces driving the coupled human-environment system, leading to 'pressures' (i.e., human activities and natural processes e.g., natural resource use), which cause chemical, physical, or biological 'stressors' (e.g., toxic chemicals, habitat alteration, invasive species) that affect the 'condition' of ecological structure, processes, and/or diversity and ecosystem services that link ecological systems, societal systems and human well-being [24]. Management actions can feed back to the system through the four types of societal and ecological responses.

The Land Degradation Neutrality (LDN) framework draws on the Driving ForcePressure-State-Impact-Response (DPSIR) framework, but with the overarching aim to counterbalance the expected loss of productive land with the recovery of degraded areas. The framework takes a multi-pronged approach, that aims primarily to avoid and reduce new degradation of land, and then to reverse existing land degradation (Avoid > Reduce $>$ Reverse). This hierarchy, based on the recognition that prevention is better than cure, articulates the priorities in planning LDN interventions [7]. The novel aspect of the LDN target that sets it apart from earlier efforts to tackle land degradation is the specific adoption of neutrality (against an established baseline) as the minimum goal. Neutrality requires that there is no net loss of land-based natural capital between time zero and the target date (2030, for the SDGs). The framework has prescribed three global (biophysical) indicators serving as proxies for ecosystem services: land cover/land cover change (water regulation and others), land productivity/NPP (food supply), and carbon stocks/SOC (nutrient cycling) against which the land degradation is monitored while being open to additional/complementary indicators [5]. A number of characteristics make LDN suitable for application in this case study:

- $\quad$ it has been posited in relation to DPSIR and can easily be tailored to DPSCR 4 ;

- it has an explicit SES focus;

- $\quad$ it is intended to be implemented at local scales; and

- the mechanism for achieving the LDN vision is through participatory integrated land use planning which is the approach the TP uses.

The guiding framework for this study is a simple composite model embedding LDN within $\mathrm{DPSCR}_{4}$ presented as a systems model (Figure 2). 


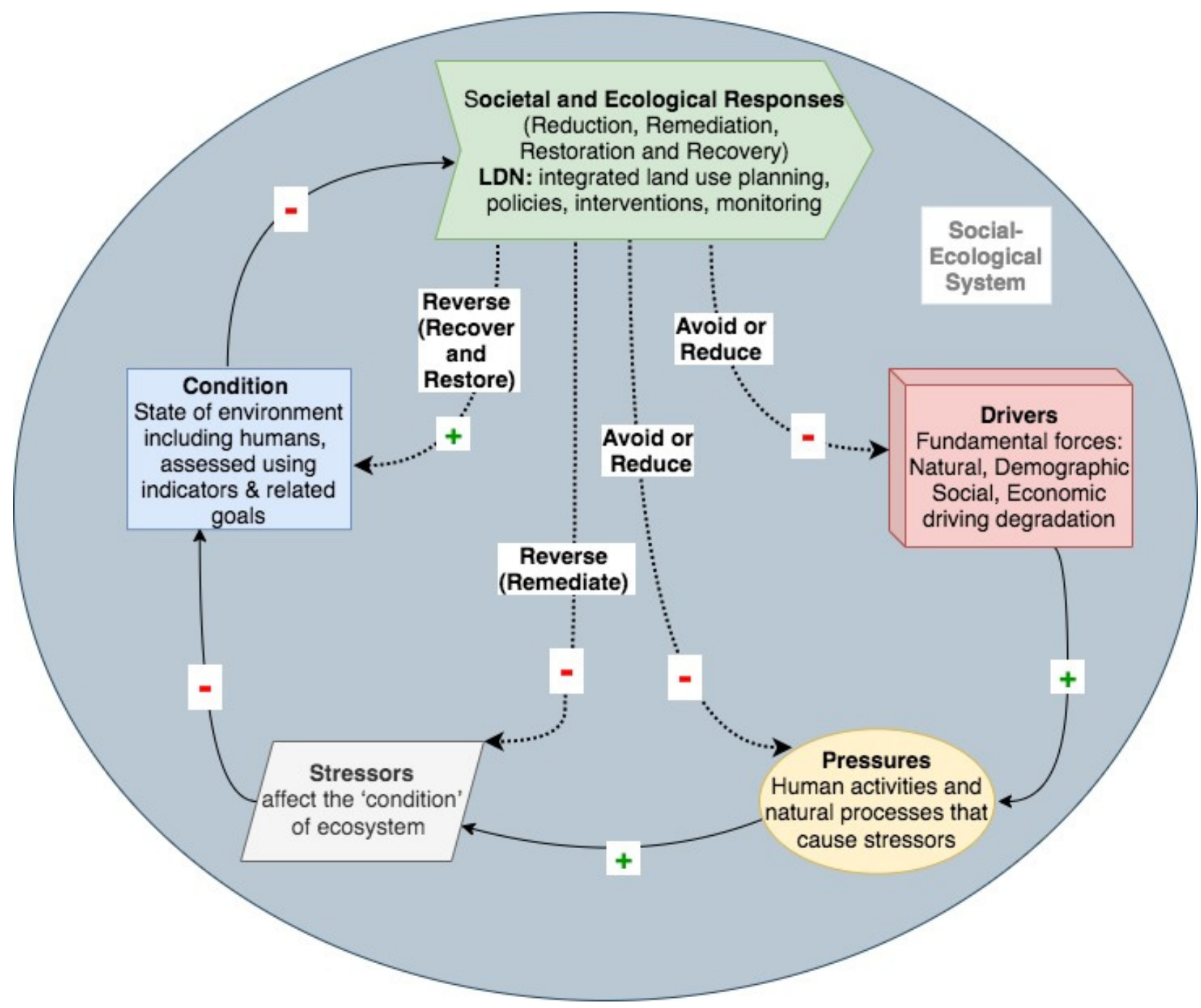

Figure 2. Conceptualizing the role of Land Degradation Neutrality within the Drivers-Pressure-Stressors-ConditionResponses $\left(\mathrm{DPSCR}_{4}\right.$ ) framework (used in the Tsitsa Project (TP)) to combat land degradation using a social-ecological systems approach. Solid arrows indicate cause-effect relationships, and dotted arrows indicate response relationships. The green ' + ' signs on the arrows show relations where a change in the cause creates a change in the effect in the same direction, the red ' - ' signs on the arrows show inverse relationships (modified from $[7,29]$ ).

\section{Materials and Methods}

Data about the drivers of degradation in the TRC were generated from three sources: key informant interviews, a workshop session, and project documentation. There are two areas of innovation in the methodology of this research. The first area of innovation is the combined general strategy of the interviews followed by more specific analysis from the workshop and project documentation, from which it emerged that there was substantive new evidence about drivers of degradation that had not been synthesized before. The second area of innovation is the use of the systems analysis approach to synthesize information from sources Sections 2.1-2.3. (outlined below) to build systems diagrams.

\subsection{Interviews}

Interview participants were selected based on their skills and position in the TP, through which they have specialist knowledge of the TP (and TRC) that is more extensive, detailed, or privileged than the general public, making them expert or key informants [34]. A list of nineteen key informants, including the researchers leading all the existing TP communities of practice (CoPs) at the time, as well as TP (research and project) manage- 
ment, were interviewed (two group interviews and fifteen individual interviews). The key informant interviews were aimed at identifying key variables of the system and how they connect, and the level of the interconnectivity of data in the TP as a transdisciplinary endeavor. Interviews were undertaken between July 2019 and January 2020 with some follow-up discussions taking place in May 2020. The interviews were intended to provide a broad overview of the key issues facing the catchment and to identify the progress and gaps of the TP to date. The need for a synthesis of the drivers of degradation in the system emerged as a gap during analysis across the key issues which was raised in the interview data and in a further review of internal project documentation.

\subsection{Workshop}

A virtual follow-up workshop, held in May 2020, was attended by 29 participants including 15 of the 19 original interviewees as well as additional representatives from various stakeholder organizations. Participants answered multiple-choice and open-ended questions around the drivers of degradation in the system, and suggested additional documents including journal articles, strategic planning documents, and internal reports, for subsequent review. There were four questions focused on drivers of degradation in the system. The first question was if and how (or where) the TP's understanding of the drivers of degradation in the TRC had been synthesized. This was followed by participants individually listing drivers of degradation in the TRC. In question 3, participants chose the three most important drivers of degradation from the combined list, and in question 4 they selected any factors that they thought should not be on the list. A derivative of the classic Analytic Hierarchy Process (AHP) method [35] was used by asking participants to assign values of importance to each of the drivers of degradation. These values informed a hierarchical analysis, out of which the top drivers were selected for further development in this paper.

\subsection{Document Review}

Data were drawn from a variety of different sources. These include:

(a) relevant internal project documents prepared for DEFF, which were identified during the interview and workshop processes (a summary of these documents and their relevance in the study is provided in Appendix A, Table A1);

(b) published literature on the Tsitsa; and

(c) supporting literature, made up of published and "grey" literature that addressed issues similar to that of the TP/TRC, but are not solely focused on the catchment. This could be literature that speaks to the wider region (e.g., [3]) neighbouring areas (e.g., [36,37]), or areas facing similar degradation contexts (e.g., [38,39]).

\subsection{Systemic Analysis}

System dynamics and systems dynamic modeling are, respectively, an approach and a tool for comprehending a system's structure across disciplines by modeling complex social and ecological events, patterns, and processes along with their key feedback loops, using systems thinking principles [40]. System dynamics helps to better represent, analyze, and understand systems, including those characterized by some uncertainty. Jay Forrester [41], known as the founder of System Dynamics, argued that one of the most powerful aspects of the system dynamics modeling approach is the breadth of data sources that can be usednamely numerical, written, and mental. The triangulation of key informant interviews, the workshop, and the combination of documents reviewed, together with integration, formed the basis of systemic analysis of the drivers of degradation in the TRC. Causal loop diagrams (CLDs) that hypothesize system behavior and identify balancing and reinforcing feedbacks were developed (Figure A1 of Appendix B), but more readable systems diagrams presented in the paper itself are not strictly according to CLD conventions; rather they use a format that is more appropriate for the DPSCR 4 LDN framework (Figure 2). The diagrams 
thus provide a systemic snapshot of expert knowledge on the key drivers of degradation in the system.

Research ethics clearance was obtained from the Wits University Ethics Committee (Clearance certificate: H19/09/13).

\section{Results}

The results are presented here in three sub-sections. Firstly, the interview and workshop results describe the data gathered from key informant descriptions of the drivers of degradation in the system. Secondly, the document analysis focuses on synthesizing data from TP documents and published literature on three emphasis points (natural drivers, land use change, and grazing management) that emerged from the interview and workshop results. Lastly, the systemic analysis presents and describes systems diagrams to improve our understanding of the interconnected social and ecological variables driving land degradation in the system, which will inform sustainable land management.

\subsection{Interview and Workshop Results}

This section presents results from the workshop which helped validate, verify, and further unpack a summary of data regarding land degradation that emerged from the key informant interviews. When participants were asked at a workshop if and how the $\mathrm{TP}^{\prime}$ s understanding of the drivers of degradation in the Tsitsa River Catchment had been synthesized, it became apparent that many were not aware of any such work having been undertaken. Six out of the fifteen respondents acknowledged that while the drivers are mentioned and shared in various ways and at various forums, they did not know of a single synthesis, as shown in this narrative thread:

"Although the drivers of degradation have been pointed out in various other forms, I can't, from the top of my head, point towards a simple and readily available document to use as a reference when planning for interventions over and above those typically employed in the project".

Other feedback noted that the project has:

"neglected this aspect to some extent. We are relying on 'received wisdom' and literature/theory e.g., on overgrazing, soil erosion, etc. and don't fully understand how these drivers work in the Tsitsa catchment context", and that, "the process of synthesizing has only started happening in the last 18 months as the CoPs and the partners start working more closely together. The more we share information the more likely it is that the synthesis will happen".

Another six out of the fifteen responses pointed to various reports, plans, and papers that spoke to the drivers of degradation in the TRC. A review of these sources is included in this synthesis.

Participants were then asked to list 'drivers of degradation in the TRC'; there were no restrictions on the number to be listed. There were 19 respondents to this question. Responses were thematically categorized, leading to some respondents bringing up two issues within the same theme, for example, if both grazing management and overgrazing were mentioned by a participant, that was counted as two responses within the theme 'grazing management/overgrazing'. 'Grazing management/overgrazing', 'physical factors', and 'governance issues' were the most frequently listed 'driver' themes (Table 1). These 'drivers' span across several categorizations within the DPSCR 4 framing and will be described in DPSCR 4 terms in the systems diagrams. It was noted that a number of these 'drivers' are interrelated, which will also be further described in the systems diagrams.

Participants selected the three most important drivers of degradation from the list in Table 1 in the TRC (Figure 3); the top choices were: physical factors such as steep terrain and erodible soils (selected by 12 of the 22; 54.54\% of participants), land use or land cover change (selected by 10 of the $22 ; 45.5 \%$ of participants), overgrazing (selected by 9 of the 22; $40.9 \%$ of participants), and disempowerment and poverty (selected by 8 of the 22 or $36.4 \%$ 
of participants). Other drivers considered to be in the top 3 were 'extreme weather' and 'fire patterns and management' (selected by 6 of the 22 or $27.3 \%$ of participants respectively). One participant commented:

"I don't think there are a top 3! They are all interconnected. But I tried".

Table 1. Drivers of degradation in the Tsitsa River Catchment listed by 19 Tsitsa Project participants.

\begin{tabular}{cc}
\hline Drivers of Degradation in the TRC & Number of Mentions \\
\hline Gazing Management/Overgrazing & 20 \\
Physical Factors (steep terrain, erodible soils) & 12 \\
Governance Issues & 11 \\
Climate and Extreme weather (droughts, storms) & 7 \\
Agricultural Practices & 6 \\
Infrastructure (poorly designed, built, or maintained) & 6 \\
Rural-urban linkages \& Migration & 6 \\
Fire patterns and management & 5 \\
Alien invasive species & 5 \\
Land use or land cover & 4 \\
Livelihoods & 3 \\
Climate change & 2 \\
Disempowerment, poverty & 2 \\
Historical socio-political factors & 2 \\
Livestock food availability & 1 \\
Deforestation & 1 \\
Land tenure & 1 \\
Fuelwood collection & 1 \\
\hline
\end{tabular}

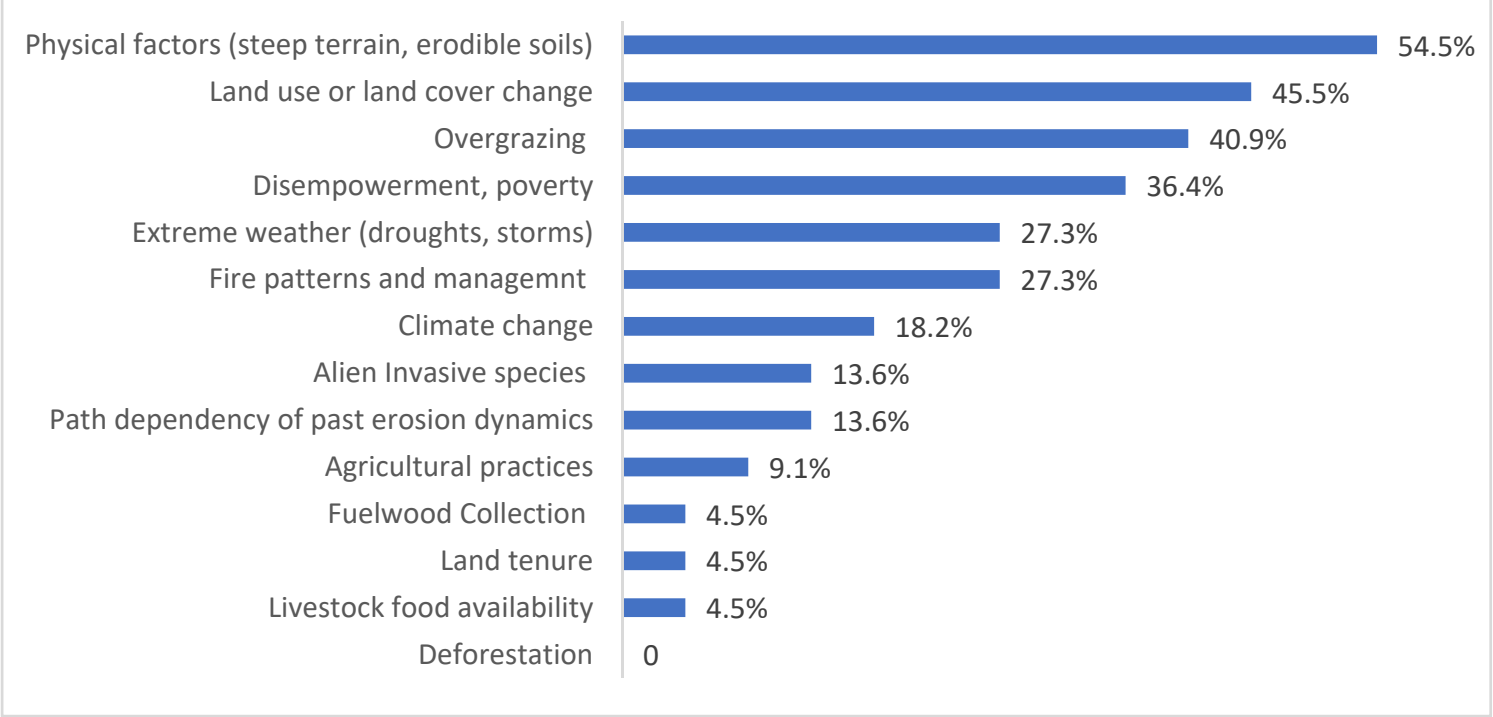

Figure 3. Selection of the three most important drivers of degradation in the Tsitsa River Catchment (TRC) from the list in Table 1 (22 participants).

When asked to select any factors that participants thought should not be on the list of drivers of degradation for the TRC, a number of participants ( 9 of the $23 ; 39.1 \%$ ) felt that all drivers must remain on the list (Figure 4). The drivers that were, however, deemed least applicable to the TRC by other participants were deforestation and fuelwood collection. 


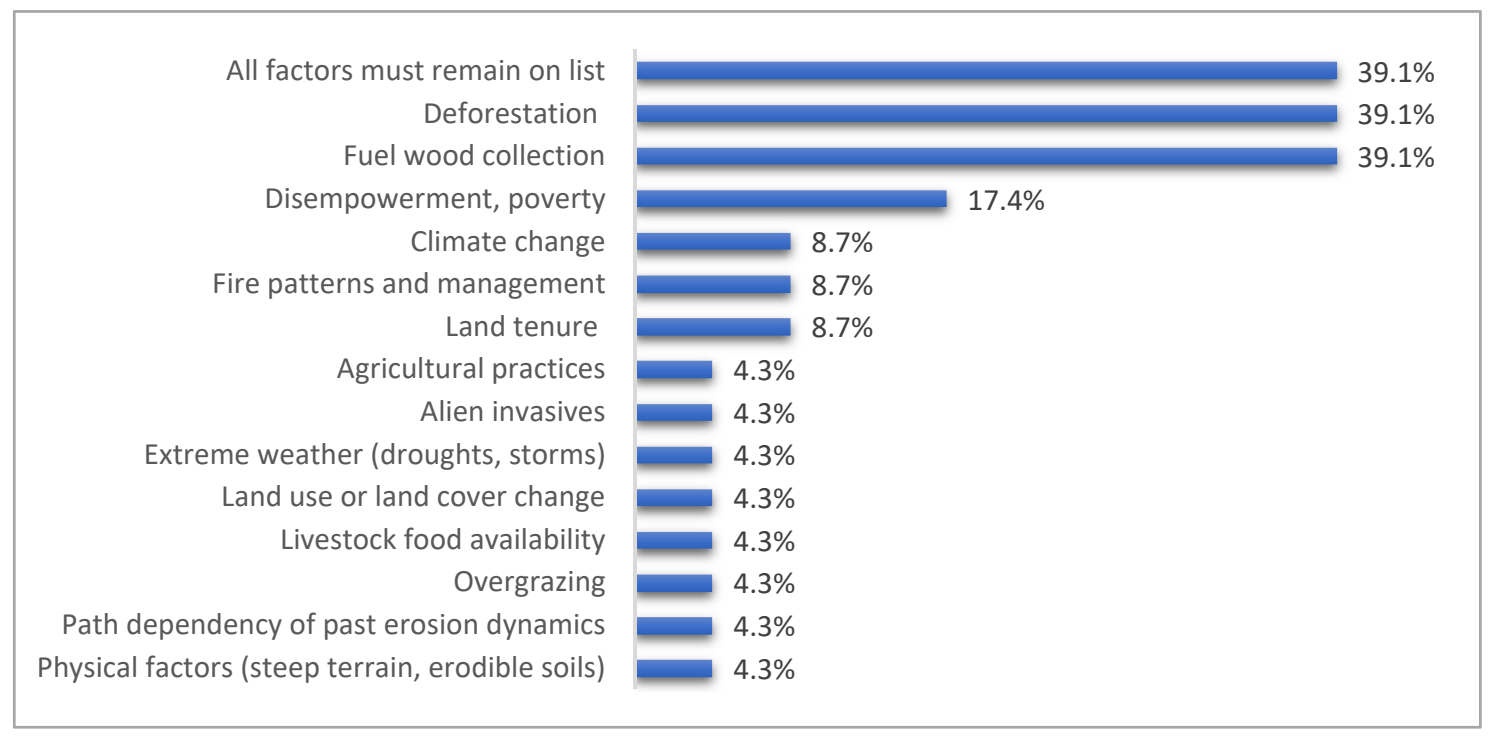

Figure 4. Selection of factors from Table 1 that participants believe should not be on the list of drivers of degradation in the TRC (23 participants).

Looking at the results from Table 1, Figures 3 and 4, according to the workshop participants, the most important factors driving degradation in the TRC were grazing management/overgrazing, physical factors such as steep terrain and erodible soils, climate and extreme weather events (droughts, storms), land use or land cover change, disempowerment and poverty, governance issues, and fire patterns and management.

\subsection{Document Analysis Results}

The workshop and interview results identified natural drivers, land use and land cover change, and uncontrolled/overgrazing as key factors leading to degradation in the TRC. These three emphasis points were explored further below through integration of relevant data from internal project documents, published literature on the TRC, and general supporting literature. These were used to inform the systemic analysis that follows.

\subsubsection{Emphasis Point 1: Natural Drivers}

Soil erosion is an important form of land degradation and is one of South Africa's most critical environmental issues [10]. Physical characteristics influencing land degradation through soil erosion include altitude, slope, runoff, soil erodibility, and soil fertility [3]. Steep topography and dispersive soils with duplex profiles predispose the TRC to soil erosion and gully formation $[13,23,25]$. There are limited options when it comes to changing the physical characteristics of a landscape and existing strategies for rehabilitating duplex soils are based mainly on experiences of working in Australia [42,43]. These strategies aim to enhance water movement and infiltration between the A-B horizon boundaries of the duplex soil profiles via the addition of clay to the sandy topsoils through two different approaches: clay spreading or clay delving [44]. Since these interventions require significant investment in labor and resources, they may be inappropriate for catchmentscale application [36].

Climatic variables have also been found to be drivers of land degradation across South Africa [3]. Gully initiation and intensification in communal lands of the Eastern Cape were found to coincide with a period of extreme rainfall events in the 1970s [43]. Workshops with communities from two villages in the catchment reported that the largest 'dongas' (deep gullies) had been present for the lifetime of the oldest residents, but the erosion in their part of the catchment was thought to have worsened from the 1960s and to be continuing today [16]. Extreme weather featured predominantly in their list of drivers of degradation, with thirteen events from the 1940s till the current decade (droughts $n=6$, 
floods $n=4$, and tornados $n=3$ ) [16]. Climate change futures for the region predict higher temperatures, decreased rainfall over the growing season, increased variability, more extreme weather events, and longer dry spells [45]. Fine-scale analysis of the TRC rainfall [46] also suggests a possible increase in rainfall intensity [16]. Increases in rainfall intensity would lead to increased runoff, reduced water retention, erosion, and flooding. Loss of vegetation cover due to drought would, likewise, increase erosion potential. There is therefore a strong likelihood that the catchment's susceptibility to erosion will increase in the future in response to climate change [26].

There is little that can be done to directly influence the physical aspects and climatic variables of a landscape; these can be considered inherent properties at the scale of the study area. These properties must. However. be understood because they affect the efficacy of potential responses. The TP posits that, in light of the study area's underlying natural drivers, dense vegetation cover will provide the best protection against degradation as surface runoff and splash erosion are limited and the flow of subsurface water is reduced. Dispersive soils are prone to water saturation and piping erosion and this should be prevented $[16,23]$. Land use practices, especially those related to grazing and cultivation, influence ground cover in the catchment and may be potential leverage points, but more data are needed.

\subsubsection{Emphasis Point 2: Land Use and Land Cover History and Futures (Driven by} Economic, Demographic and Social Factors)

The land cover distribution for the focus area of the TRC in this case study is comprised mostly of grassland $(71.8 \%)$ with some plantations ( $7.0 \%$ exotic pine and eucalyptus species) and cultivated fields (8.8\%: subsistence 5.3\%; commercial 3.5\%) [47]. The two main types of landholdings are communal and private land. The larger portion (62\% or 124,000 ha) of the middle and upper catchment is private land mainly under white ownership, comprised of larger commercial farms, and plantations; scattered urban and semi-urban centers [24].

Landscapes and livelihoods change over time in response to local and external drivers, including changing modalities of state interventions in the rural domain. According to Hebinck and others [37] (p. 324), "this necessitates conceptually and empirically infusing a time dimension and a robust historical framing in any analysis of land use change". Forced removals and resettlement implemented by the Apartheid regime from the 1960s onwards contributed to rapid population growth in the communal land [16,48]. The Transkei's population increased threefold from 800,000 in 1904 to 1,300,000 in the mid-1950s to $2,600,000$ by 1981 [48]. The majority of the catchment's population currently reside in lowdensity rural villages on 76,000 ha of communal land (of the former Transkei homeland) which is held on behalf of the National Government under the authority of Tribal chiefs [24]. The communal land, found mostly in the middle and lower parts of the catchment, is colocated with the more erodible soils [25]. A review of land degradation in South Africa showed considerably worse land degradation in communal areas than in commercial farming areas and, while the rate of degradation in communal areas was increasing, the rate in commercial areas was decreasing [3]. The results for the TRC concur with findings elsewhere in South Africa that land use types and land tenure systems are important predictors of soil erosion (though not necessarily the direct cause) [3].

Land use in the communal areas of the TRC is dominated by rural subsistence farming [24]. Cultivation was once widespread, but a study of two villages in the catchment found that field cultivation has almost entirely ceased and is now confined to gardens next to the homesteads [16]. Village residents gave the main reasons for this as drought, lack of manpower to plow, lack of access to tractors and machinery, theft of fences, soil erosion and reduced fertility, and a lessened need to grow crops due to the introduction of child subsidies in 1999 [16]. This illustrates how the linked social and ecological aspects of the system have contributed to the disuse of fields, which was found to be one of the main (direct and indirect) drivers of severe erosion and land degradation in most parts of the Eastern Cape Province [43]. 
Demographically the villages are in a state of flux, which influences land use. Freedom of movement after the 1994 democratic elections enabled a large out-migration as individuals and families moved to urban areas in search of better opportunities. Freedom of movement has also allowed more learners to join their families in urban centers for high school education. These factors have contributed to a clear decline in population numbers, which in turn has reduced the areas cultivated [16]. The study area is experiencing significant out-migration, resulting in a population decrease of $19 \%$ (from 55,797 to 45,043 people) between 2001 and 2011 [49], further exacerbating the disuse of fields as the potential labor force decreases. The disuse of crop fields by smallholder farmers in the communal areas is part of a wider trend across South Africa [37,39]. De-agrarianisation is, however, not a linear process. Crops are sometimes planted opportunistically on 'deactivated' fields when it rains. Hebinck and others [37] argue that having the option to farm at any time remains important to local identity and sense of belonging as well as a livelihood safety net for people retrenched or retiring from urban employment. The range of linked social and ecological factors discussed above make a return to large scale field agriculture unlikely to be a viable intervention for communal villages. The lack of field-scale irrigation in the communal areas of the TRC also means that crops are subject to severe weather events such as the ongoing drought [16].

Land use change can be monitored at a particular resolution both currently and historically and offers a valuable tool to obtain various types of information about drivers of degradation in the catchment.

\subsubsection{Emphasis Point 3: Uncontrolled/over Grazing in the Catchment}

Theories, models, and approaches to grazing and fire management have varied over time from very controlled, to more adaptable and "natural" approaches, but some commonalities across models are that stocking rates matter and that plants need rest to survive over time [26]. The TRC represents a microcosm of land management in South Africa in that there are currently two primary grazing management systems in place: a more sustainable rotational grazing model on privately owned land and an unsustainable continuous grazing model on communal land [25]. Overgrazing came through very strongly in the workshop as a perceived driver of degradation in the system. The Webster Dictionary defines the term overgraze as: "to allow animals to graze (as a pasture) to the point of damaging vegetational cover" (Merriam Webster Dictionary available at http:/ / www.m-w.com/cgi-bin/dictionary). The term 'overgrazing' implies grazing at a higher level than required to meet a specific management objective [50], whilst the term is strictly defined it is used in a variety of ways depending on the perception of the people.

For population ecologists, overgrazing is often associated with carrying capacity $(\mathrm{K})$, which has been defined as the population stocking numbers above that which the population will grow [50]. In the TP and TRC where the objective is the sustainable management and utilization of the natural resources by livestock, grazing capacity, defined as 'the land area required to support a single large stock unit (LSU) for an extended period of time without resulting in declines in condition of the resource' [51] (online), is a more useful measure in relation to overgrazing. Grazing capacity indicates how many hectares are needed per large stock unit (ha/LSU). The long-term grazing norms for the Grassland biome provided by the former Department of Agriculture, Forestry, and Fisheries (DAFF) is set at 4-6 ha/LSU [52]. A study on grazing capacities based on MODIS (250 m spatial resolution) forage production long-term, means five sites across the study area were found to have long-term grazing capacities of $4-4.9$ hectares per large stock unit (ha/LSU) in lower catchment sites, but significantly lower grazing capacities of 7.7-7.8 ha/LSU were found in the upper catchment sites due to lower forage quality in a more acidic environment [53].

Livestock numbers declined during the 'betterment planning' (rural development planning implemented in the former homelands) from 1965 [54], but current numbers and trends are unknown. Some households interviewed perceived that livestock numbers have decreased over time while others suggested that livestock numbers had increased due to 
the breakdown of controls on the number that can be owned [54]. There is no intentional aim to manage stock numbers which are thought to fluctuate around the maximum number that can survive on natural grazing and can vary with drought, theft, and disease [25]. During winter, grass availability and quality are very poor and the feeding of animals is limited due to high feed costs [25]. Data on actual stocking numbers across the catchment are needed to determine whether the livestock numbers are within or above the grazing capacity. If the stocking numbers are within the long-term grazing capacity, this could point to a livestock management problem rather than an overstocking problem. Livestock in the communal land is left free to graze in and around the village on a daily basis with little management beyond being brought back to the village at night for safety [54]. This results in no recovery period for the rangelands. Following the change in government in 1994, the migration to the cities has left fewer people to look after stock [16].

Democratic changes after 1994 caused tension between traditional leadership, who lost some authority to govern natural resource use, and elected councilors, which has resulted in a perceived breakdown of local governance systems leading to increased theft of fences and livestock [16]. Theft is a disincentive to farming in both the communal and commercial areas. The lack of fences changes the way that grazing is managed, and the land is used. There is also an absence of rangeland institutions in this area [54]. This lack of control results in livestock grazing on abandoned fields which, due to the nature of the soils, are particularly susceptible to sheet erosion.

\subsection{Systemic Analysis Results}

3.3.1. The Drivers, Pressures, and Stressors Causing Land Degradation in the Tsitsa River Catchment

The factors that were identified through the interviews, the workshop, and document review as having causal links to land degradation were categorized in terms of DPSCR with special consideration to their impact at the relatively small scale of the study area (Table 2). At larger scales, climate change is an outcome of human activities (or pressures) that stress the landscape, and a change in human activities could relieve the impacts of climate change. Likewise, land degradation at large scales acts as a driver of climate change through the emission of greenhouse gases and reduced rates of carbon uptake [55]. At the scale of this study area, however, climate change would be considered a fundamental force or driver, and land degradation is the undesirable resulting condition.

The DRSCR 4 from Table 2 are arranged into two systems diagrams. Figure 5 illustrates how the drivers, pressures, and stressors are interrelated, and would not have the same outcomes if they were acting independently of one another. Figure 6 highlights the entry points and systemic pathways through which potential responses are hypothesized to impact the system. The variables are categorized in the diagrams below, as noted in the key at the bottom of the figures, as follows:

- the light red boxes show fundamental drivers of degradation (which could be natural or anthropogenic);

- the orange ovals show pressures (which are defined here as human activities and processes that cause stressors);

- the grey parallelograms show stressors (which could be natural or anthropogenic);

- the blue rectangles show the condition (in this case, the resulting condition of interest is land degradation); and lastly,

- the green arrows show interventions (which do not fall into the other variable categories).

Figure 5 maps the relationships between some of the key variables driving land degradation in the Tsitsa River catchment, showing why coordinated, integrated, and cross-sectoral interventions are required to reduce degradation and improve sustainable livelihoods in the area. 
Table 2. Drivers Pressures Stressors Condition and Responses $\left(\mathrm{DPSCR}_{4}\right)$ for the Tsitsa River Catchment (TRC).

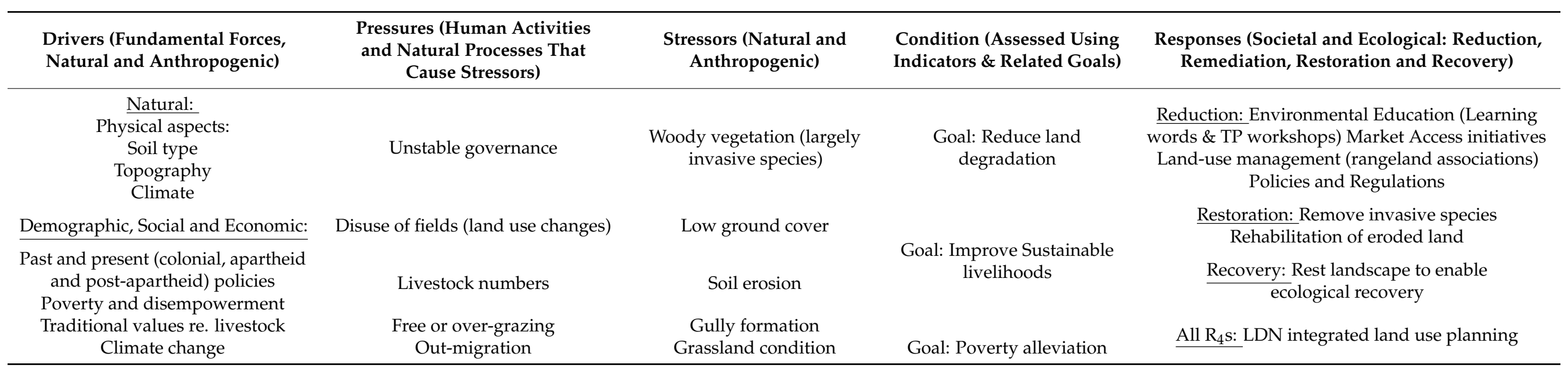



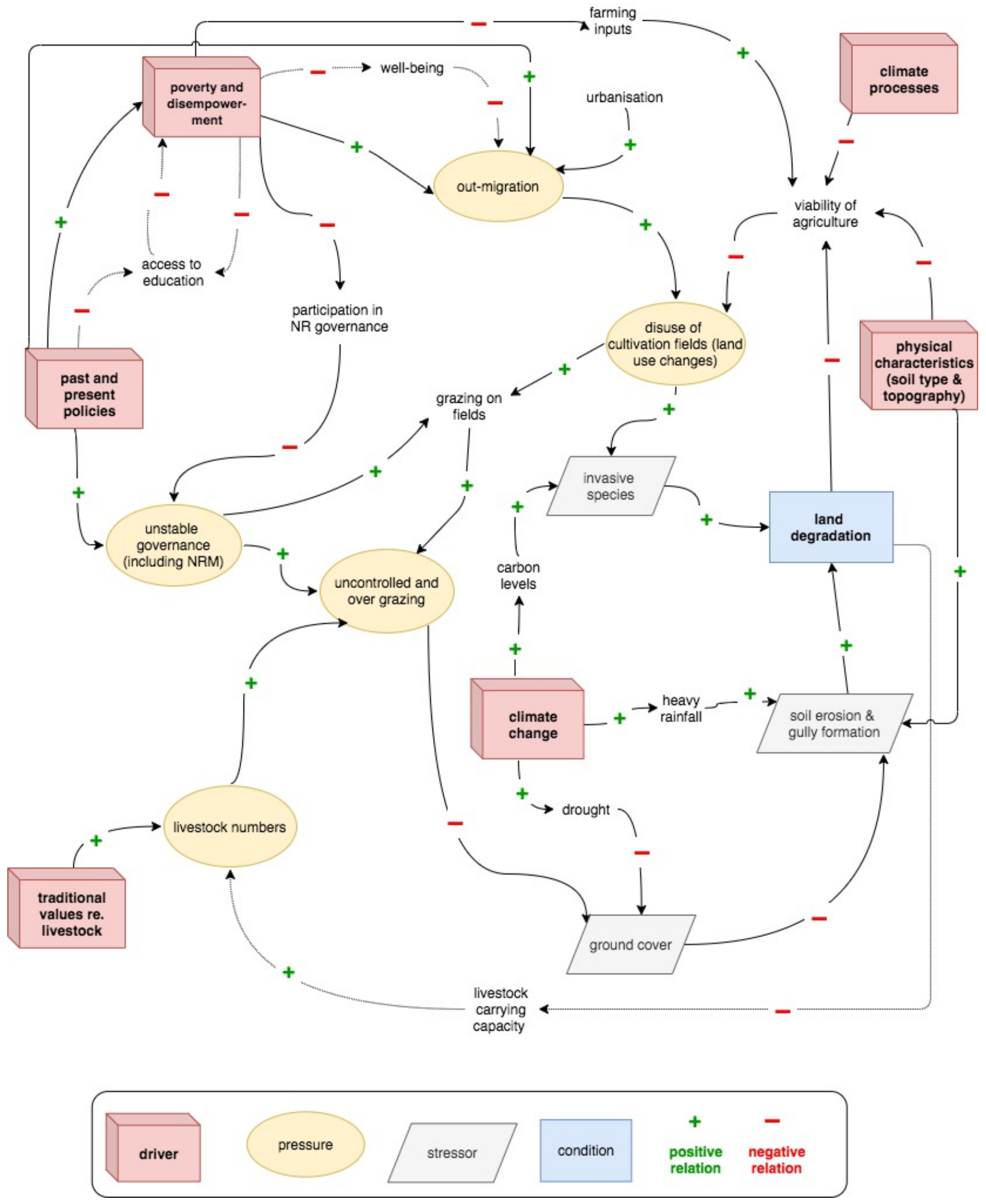

Figure 5. Drivers, Pressures, and Stressors that cause land degradation in the Tsitsa River Catchment (TRC). 

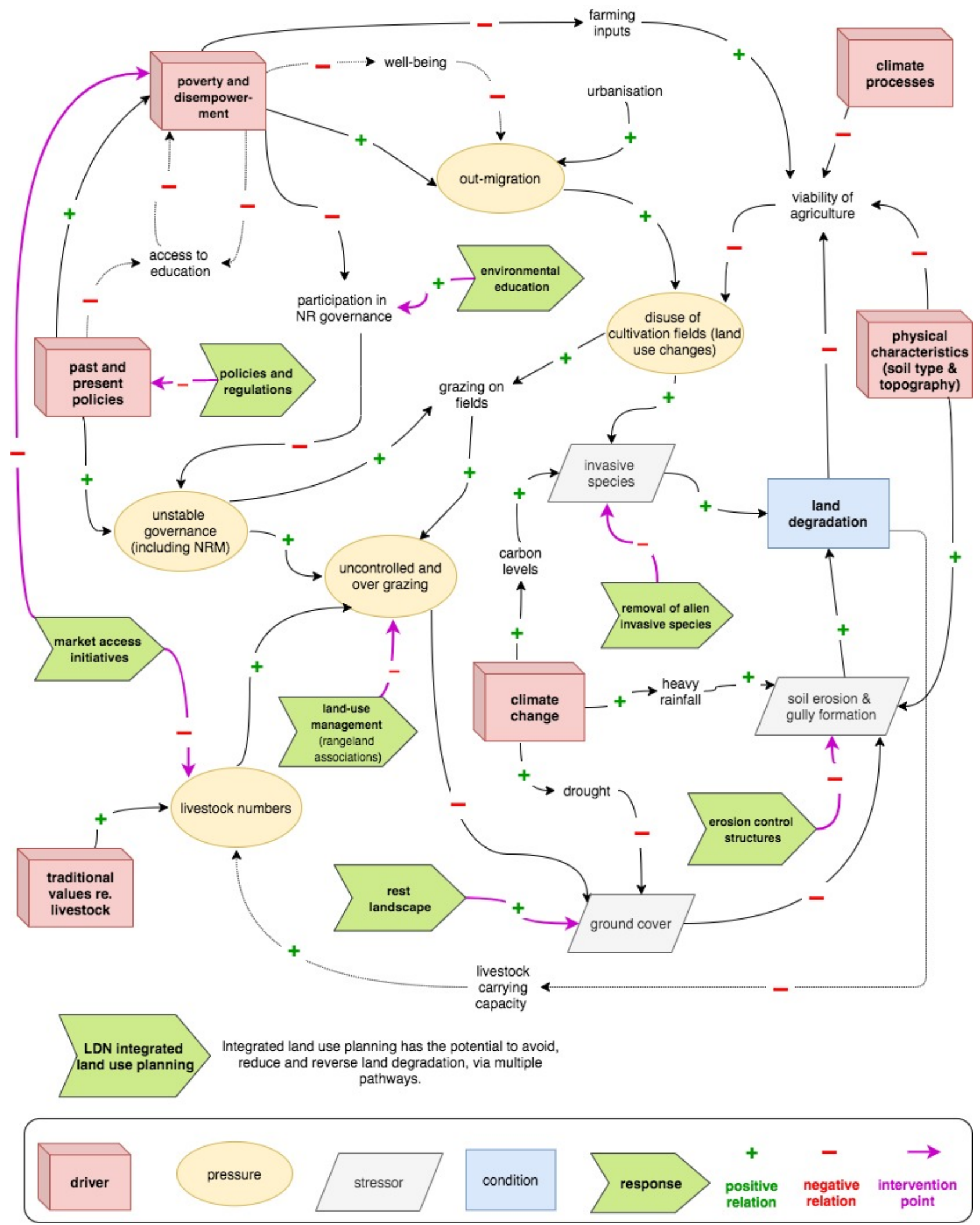

Figure 6. Drivers of degradation and potential responses being considered by the Tsitsa Project (TP) to reduce degradation and improve sustainable livelihoods in the Tsista River Catchment (TRC).

In the lower right side of the diagram is the (undesirable) condition of interest, land degradation, which is exacerbated by soil erosion, gully formation, and invasive species (the green ' + ' signs on the arrows show relations where a change in the cause creates a change 
in the effect in the same direction-for e.g., the more climate change, the more soil erosion and gully formation, causing more land degradation; the red '- ' signs on the arrows show inverse relations, where a change in the cause creates a change in the effect in the opposite direction-for e.g., as drought increases, ground cover decreases).

If we shift our focus to the fundamental drivers of degradation in the diagram, we see that past and present policies (such as Apartheid policies which forced large numbers of indigenous people on to the Transkei, and restricted their access to education) fuelled a reinforcing cycle of poverty and disempowerment of the population in the communal lands which made the prospect of out-migration appealing. Post-1994 policies (such as freedom of movement) enabled widespread out-migration as people moved out of the catchment in search of opportunities.

Out-migration contributes to the disuse of cultivation fields. The physical characteristics (such as soil type and topography), climate processes, and existing land degradation of the catchment necessitate farming inputs for the viability of agriculture; but poverty and disempowerment preclude farmers from acquiring these inputs. These barriers to viable agriculture further drive the disuse of cultivation fields. With increasing disuse of fields, the number of invasive species growing on fields increases, contributing to land degradation, which reduces the viability of agriculture thus leading to further disuse of cultivation fields in a reinforcing cycle. Climate change increases atmospheric carbon levels which increases invasive species plant growth. Climate change also increases the likelihood of both heavy rainfall (which directly increases soil erosion and gully formation that the physical characteristics predispose the landscape to) and drought (which decreases ground cover, in turn increasing soil erosion and gully formation) to cause further land degradation.

Past and present policies (driven by broader national issues and the breakdown of local governance systems) have resulted in unstable governance. Poverty and disempowerment have a negative effect on participation in NR governance, reinforcing the unstable governance, which enables uncontrolled and overgrazing. Uncontrolled and overgrazing reduces ground cover, increasing soil erosion and gully formation driving land degradation. Land degradation reduces the livestock carrying capacity of the area, resulting in increased livestock deaths which decreases stock numbers, thus allowing the landscape to recover and reduce land degradation.

Increasing disuse of cultivation fields together with unstable natural resource management (NRM) governance, leads to grazing on fields, which is part of a wider issue of uncontrolled and overgrazing, also driven by traditional values that emphasize the desirability of high livestock numbers.

\subsubsection{The Tsitsa Project Response to Land Degradation}

One of the ways that the TP is different from other state-funded restoration projects that typically focus on technical solutions to degradation, such as physical erosion control structures, is its explicit transdisciplinary SES approach. This includes ensuring that community perspectives and knowledge are integrated within the project, which is considered key to its long-term sustainability. Livestock numbers are culturally important to the community with less focus on their productivity which drives range degradation and low cash income [25]. Participants at a 2015 workshop in the Sinxaku villages in the catchment did not believe livestock to be a cause of erosion [16], though perceptions may have since changed. Despite livestock and grazing controls being a sensitive issue, the community responded positively to the idea of a ranger system that allows a rotational rest period of rangelands, similar to the one that existed in the past [16]. Such a ranger system would work with an agreed set of rules, developed by the community with the help of researchers, to monitor and limit activities that start or increase erosion [16].

The Tsitsa Project supports DEFF's interventions through: advice on where different measures should be applied (based on biophysical monitoring data and participatory community mapping); identifying areas at risk of erosion but not yet degraded; growing vetiver in household gardens for use in the rehabilitation (thus creating income for households); supporting livestock associations, giving advice on livestock management and facilitating 
links to marketing opportunities; biophysical and social monitoring; building capacity of community members to participate in these activities and to become involved in NRM governance; building internal and external networks; and bringing these together in an integrated plan applied at the village or village group level [26]. These activities are already happening. The systems diagram (Figure 6, below) positions the TP's responses within their systemic context to demonstrate how they are linked. It shows the pathways (drivers, pressures, and stressors) through which the responses are hypothesized to affect the system. The analysis provides a basis for integrated planning. Deeper individual analysis of each potential response can identify alternate potential pathways and impacts, but part of intervening in complex systems is accepting that responses may have unforeseen or unintended consequences.

The dynamic approach of the TP has enabled the implementation of responses to target various drivers and pressures placed on the landscape as follows (displayed graphically in Figure 6):

- Environmental education envisioned to improve the capabilities of communities to participate in natural resource governance.

- Market access initiatives such as 'Meat Naturally' incentivize livestock owners to maintain livestock quality (as opposed to focussing mainly on quantity) by providing an avenue to sell healthy livestock at a good price, which would decrease active livestock numbers. This would be an indirect way of managing land use to improve the viability of livestock as a sustainable livelihood and could lower poverty and disempowerment.

- Policies and regulations should be explicitly designed to reverse the negative impacts of past and present policies on the social-ecological condition of the area.

- Land use management such as rangeland associations would decrease uncontrolled and overgrazing.

- The removal of alien invasive species directly decreases the number of invasive species on the landscape.

- Efforts to rest the landscape would allow necessary plant growth to increase ground cover.

- LDN integrated land use planning has the potential to avoid, reduce, and reverse land degradation, via multiple pathways.

- DEFF has also invested considerably in direct rehabilitation using erosion control structures to reduce soil erosion and gully formation.

In addition to responses managed by the TP listed above, the project must consider the impacts of other activities and plans on the area, and the project. For instance, there is a Forestry Master Plan to plant seven-hundred-thousand trees in the Eastern Cape in the near future [56]. The TP must consider whether the TRC will be affected and the impact of such an intervention on land degradation, sustainable livelihoods, and poverty alleviation.

\section{Discussion}

\subsection{Synthesizing Drivers, Pressure, and Stressors Contributing to Degradation in the TRC}

The application of a systems analysis as presented in this paper highlights how the environmental problems facing the TRC result from a set of interrelated core challenges (centered around biophysical aspects, overgrazing, and land use) that manifest through the interplay between various social and biophysical factors. Achieving effective, sustainable environmental governance requires a good understanding of the system drivers and consequences in the form of the complex patterns of interdependencies connecting people and ecosystems within and across scales [5]. Figures 5 and 6 present a systems perspective in terms of the DPSCR 4 that influence land degradation in the TRC, highlighting some key SES linkages relevant for sustainable land management. While the physical characteristics, such as dispersive duplex soils, are natural drivers that predispose the TRC to soil erosion and gully formation (stressors), it is the interplay between natural and human drivers and pressures, including forced resettlements, clearing and subsequent disuse of fields, and uncontrolled grazing (all of which exist in a socio-economic context characterized by poverty and poor governance) — that cause the resulting widespread erosion and land 
degradation. This aligns with Kakembo and Rowntree's [43] finding that the main drivers of severe erosion in other parts of the rural Eastern Cape Province are the erodible soils in combination with overgrazing and disuse of fields linked to poor governance and poverty.

The historical context also has a bearing on the current social and ecological state and drivers of degradation in the catchment. A synthesis of some of the historical and current South African policies that could be drivers of either degradation or rehabilitation in the TRC can be found in Rowntree and others [16] (pp. 37-44). Poor natural resource governance and management exacerbated by the reduction of the authority of traditional leaders in the democratic era have resulted in few grazing controls and grazing on abandoned fields, which exacerbates soil erosion. It is interesting that 'disempowerment and poverty' (the two variables were coupled for this study because of their close reinforcing relationship, but can also be uncoupled) was selected by eight participants at the workshop as being in the top three drivers of degradation in the system but it was considered by four as not belonging on the list of drivers at all. The two-way relationship in which poverty causes environmental degradation and environmental degradation exacerbates poverty, termed the Poverty-Environment Nexus (PEN), has been described for other degraded developing contexts in Africa [57-59]. The over-simplification of the PEN that resulted in the poor being blamed for degradation $[57,58]$ has been challenged, recognizing the complexity of this nexus in relation to sustainable development [60]. From a systemic point of view, the systems diagram (Figure 5, further elaborated in Appendix B) shows how poverty and disempowerment became entrenched and play a role in driving degradation through multiple reinforcing pathways. Cycles of poverty and disempowerment make catchment residents vulnerable and limit their coping strategies and ability to participate in local governance processes. In addition, the underdeveloped rural context makes poverty alleviation a (government) priority.

There is growing recognition within the TP and beyond of the role traditional knowledge and practices can play to sustainably combat degradation and improve people's lives in the long term. The TP emphasizes the importance of input and buy-in of communities and, given its applied praxis focus, the project will need to reconcile/address the disconnect between scientific and community beliefs. This is especially relevant with regards to overgrazing and grazing management, which was the most prevalent driver listed by workshop participants, but which communities surveyed do not necessarily see as a cause of land degradation; rather they wish for increased livestock numbers [16]. There is some evidence that communal grazing systems and associated 'overgrazing' do not necessarily degrade the range condition relative to management systems based on a notional carrying capacity. An Eastern Cape case study showed that communal grazing lands, considered 'overgrazed', had only slightly higher erosion rates than those from the land under 'optimal' grazing, that is grazed at a level considered not to exceed the carrying capacity of the land [61]. The question of whether stock numbers or management practices play a bigger role in the condition of the landscape remains a key debate $[62,63]$. There is an argument that by using management practices such as rotational grazing, greater stock numbers can be supported [64]. This is the underlying principle being advocated through rangeland associations [16], the formation of which the TP is facilitating.

Furthermore, there is no consensus among scientists on the role of overgrazing as a key driver of degradation, with some ecologists arguing that erosion and degradation in the Eastern Cape grazing systems (such as the TRC) are driven more by rainfall events and other factors than by overgrazing [61]. The Residual Trends (RESTREND) method [65] may be useful for controlling the effects of rainfall in order to detect human-induced land degradation at a regional scale by identifying areas where there has been a reduction in production per unit rainfall. The exact cause of the negative trend, e.g., overgrazing by livestock, must be more closely investigated. More data on perceived overgrazing are needed to assess its role as a driver of degradation in the system. Recent soil studies show that relatively small areas are very sensitive to erosion and can benefit significantly from increased vegetation cover $[13,23]$. 
While subsistence fields currently make up only $5.3 \%$ of the land use in the study area [47], the impact of field disuse on degradation should be explored further because duplex soils are particularly susceptible to land degradation when cleared [42]. A case study of historical land-use change and erosion in a communal Eastern Cape area showed that the most severe erosion was associated with cultivated land that had been abandoned and reverted to grazing land from the 1960s, and not from land that had been under grazing since the 1930s [61].

The drivers of land degradation in the TRC reflects certain core challenges that occur repeatedly across landscapes with similar social-ecological contexts. Other former homelands in South Africa, such as Venda in current day Limpopo, have similar sociopolitical histories and face similar challenges as the TRC with regards to poverty and land degradation [59]. There are, however, some ways that the drivers of degradation in the TRC contrast with other communal areas in South Africa. Fuelwood is the dominant source of energy and a major contributor to woodland degradation in other communal areas in South Africa [38]. In contrast, fuelwood collection did not feature strongly as a driver of degradation in TRC in either the workshop responses or the document review, suggesting that it may not play a prominent role as a driver of degradation in the system. This corresponds with the finding that the number of households with access to electricity in the catchment more than tripled from 2026 to 6663 between 2000 and 2011 [49]. Survey results from the Sinxaku villages, however, suggests that even when electricity is used for lighting, wood is still a preferred energy source for cooking and heating [16], corresponding with the majority of rural households in southern Africa [66]. When asked about their use of natural ecosystem resources, firewood collection was an overwhelming response in Sinxaku villages but little wood is in fact collected from the local area as most that are used in households on an everyday basis is purchased from a plantation and brought in by the small truckload [16]. Wood for ceremonial purposes is collected from the local environment [16]. The impact of fuelwood collection on livelihoods and degradation in the area is worth exploring further. Encroachment of grassland by woody vegetation (thorn trees) is seen as one sign of degradation, so removal of fuelwood from alien clearing and woody encroachment could be a positive intervention.

\subsection{Responses to Avoid, Reduce, or Reverse Land Degradation in the TRC}

Restoration practices in Africa must be carefully tailored to the local context. The South African DEFF's provision of funding and involvement in the TP is an important step beyond business-as-usual management responses that counter land degradation through the restoration of ecological infrastructure. Arnold and Wade's [20] characterization of systems thinking guided the process of characterizing the drivers, pressures, and stressors that affect the condition of the TRC, as well as the way these characteristics feed back into each other to systemically understand land degradation to inform sustainable land management (responses) in the TRC. This synthesis will inform the TP as DEFF's flagship restoration research-praxis project by enabling the project to systemically position and analyze a range of existing and potential future responses within the DPSCR 4 framework. This synthesis also highlights the importance of tailoring responses in the TRC to meet the goals of restoration and income generation/poverty alleviation simultaneously.

Responses could be targeted toward LDN. The TP's commitment to work with communities to implement appropriate and sustainable interventions has led the project to start developing multiple integrated restoration plans at a nodal scale, which could be designed to feed into LDN planning at sub-catchment and catchment scales. There has been some integration in an initial 2018 rehabilitation plan that was drawn up for the project [25]. Some key aspects of the plan include attention to social-ecological linkages, capacity development, avoided degradation and monitoring, evaluation, reflection, and learning. Further work on integrated rehabilitation plans for three specific nodes that are pilots within the catchment is currently underway (TP draft document: 'Elangeni node-Integrated implementation plan 2020'). 
The LDN approach within the responses category comprises the counter-balancing of anticipated losses in land-based natural capital with planned gains. The LDN hierarchy aims to avoid, reduce, and then to reverse land degradation. Many parts of the TRC are already degraded, but the options in terms of LDN responses should be geared towards avoiding the degradation of currently functioning systems, followed by reducing future degradation and reversing existing degradation. Incorporating land degradation neutrality into existing planning processes can shift land management in the TP from a reactive space into a proactive sustainable space. In addition to having an understanding of the current situation, LDN planning must consider potential future scenarios for development that could affect land degradation in the study area. In this regard, there is expected to be significant afforestation in the Eastern Cape in the near future. Seven-hundred-thousand trees are planned to be planted to meet the fifteen-year global wood shortage and for poverty alleviation [56]. The planting of trees ties into global and regional restoration initiatives such as AFR100, which targets 100 million hectares (Mha) of land in Africa for 'reforestation' by 2030, and within which South Africa has committed 3.6 Mha [67]. This extensive tree planting is framed as 'reforestation' to reduce atmospheric $\mathrm{CO}_{2}$, but most targeted areas in Africa are grassland and savanna biomes, and the social, economic, and ecological effects of converting such areas to plantations are not well understood [68,69]. Critics of such initiatives argue that while the restoration of pre-existing forests is effective in terms of climate change mitigation, plantation forestry is not [68]. Furthermore, the top-down implementation of plantation forestry ignores local concerns over land tenure, competition with agriculture, and conservation, and imposes a single dominant land use for generations to come [68]. A systemic analysis of the effectiveness of tree planting to alleviate degradation and as an avenue for sustainable livelihood creation in the TRC needs to be conducted.

Land degradation severely impacts the livelihoods of rural communities in South Africa more broadly, and in the TRC specifically. Recognizing that land degradation is a social-ecological phenomenon that reduces, over a period of time, the capacity of the land to provide ecosystem goods and services to its beneficiaries, the systemic analysis in this paper has shown the importance of understanding both the social and biophysical drivers of degradation and the way that these drivers interact to place pressure on the landscape. The TRC is an example of a region where carefully planned changes in land use and management could produce dual benefits of improving landscape conditions and sustainable livelihood opportunities. As such, the region is illustrative of the potential of integrated planning processes to support achieving land degradation neutrality targets within the context of the UN Decade on Ecosystem Restoration and the 2030 SDG agenda.

\section{Conclusions}

Land degradation in rural South Africa is a major threat to livelihoods with people being vulnerable due to poverty and a lack of integrated natural resource planning. A social-ecological system of understanding the drivers of degradation in the Tsitsa River Catchment (TRC) is essential for informing sustainable land management. A systems approach was used in this study together with two frameworks, the Drivers-PressuresStressors-Condition-Responses (DPSCR) and Land Degradation Neutrality (LDN) frameworks. Innovative data collection techniques of coupling interviews with workshops and systems diagramming resulted in the identification of the key drivers of degradation, and the linkages between them, some of which would likely have been overlooked using only a single approach. Physical and climatic variables, changes in land use and land cover, and overgrazing were identified as key factors leading to degradation. An integrated sociological and ecological study provided a basis for planning changes in land use and management that could produce dual benefits of improving landscape conditions and sustainable livelihood opportunities.

Author Contributions: This research article has several authors; their individual contributions are specified below: Conceptualization and methodology, A.I., M.C.S. and J.K.C.-H.; investigation, data 
curation, and validation, A.I.; foundational analytical work within the broader Tsitsa Project that this paper builds from K.R. and B.v.d.W.; broader literature and project documentation contributions A.I., K.R. and B.v.d.W.; formal analysis, A.I., and J.K.C.-H.; writing-original draft preparation, A.I.; writing-review and editing, M.C.S., J.K.C.-H., K.C., K.R. and B.v.d.W.; supervision, M.C.S., J.K.C.-H., and K.C.; \& funding acquisition, M.C.S. All authors have read and agreed to the published version of the manuscript.

Funding: Funding for this study, (PhD scholarship and research costs) has been provided to Mary Scholes through her DST-NRF research chair in System Dynamics. The research and implementation of the broader Tsitsa Project has been funded by the Department of Environment, Forestry and Fisheries (DEFF), Chief Directorate: Natural Resource Management Programmes (NRM), Directorate: Operational Support and Planning. The contents of this paper do not necessarily reflect the views and the policies of DEFF, Chief Directorate: NRM, nor does the mention of trade names or commercial products constitute endorsement or recommendation for use.

Institutional Review Board Statement: The study was conducted according to the guidelines of the Declaration of Helsinki, and approved by the Ethics Committee of the University of the Witwatersrand (protocol code H19/09/13, date of approval 13 September 2019).

Informed Consent Statement: Informed consent was obtained from all subjects involved in the study.

Data Availability Statement: The data collected by the authors of this study are available on request from the corresponding author. The data are not publicly available due to the need to comply with the ethics clearance certificate obtained, from the University of the Witwatersrand, for this study. Restrictions may apply to the availability of third-party data. Data obtained through Tsitsa Project reports and documentation are available upon request from info.tsitsaproject@ru.ac.za with the permission of the project manager.

Acknowledgments: The Rhodes Restoration Research group (within the Department of Environmental Science), the Institute for Water Research and the Geography Department at Rhodes University for providing access to project documents for analysis. The Department of Forestry, Fisheries and the Environment (DFFE), for being an active research participant and partner to the Tsitsa Project. Funding for this research was provided by my research supervisor, Mary Scholes, who holds a Research Chair at the University of the Witwatersrand Johannesburg. Her Research Chair is funded by the Department of Science and Innovation and the National Research Foundation of South Africa.

Conflicts of Interest: The authors declare no conflict of interest. The funders had no role in the design of the study; in the collection, analyses, or interpretation of data; in the writing of the manuscript, or in the decision to publish the results.

\section{Appendix A}

Table A1. Internal project documents that were used, together with key informant data and published literature, to develop the synthesis of drivers of degradation in the TRC. These documents are available from the Tsitsa Project, either on the website (https:/ / www.ru.ac.za/tsitsaproject/) or upon request (info.tsitsaproject@ru.ac.za).

\begin{tabular}{|c|c|c|c|}
\hline Author(s) & Date & Title & Type \& Relevance of Document \\
\hline $\begin{array}{l}\text { Botha, L., Rosenberg, E., } \\
\text { Biggs, H., Kotschy, K. and } \\
\text { Conde-Aller, L. }\end{array}$ & 2017 & $\begin{array}{l}\text { Ntabelanga-Lalini Ecological } \\
\text { Infrastructure Project (NLEIP) } \\
\text { Participatory Monitoring, } \\
\text { Evaluation, Reflection \& Learning } \\
\text { (PMERL) Framework }\end{array}$ & $\begin{array}{l}\text { Internal TP report, articulates the project's } \\
\text { intention to integrate the interests of people } \\
\text { and nature, communities and landscapes, in } \\
\text { a social-ecological systems framework, and } \\
\text { explains the PMERL approach to monitoring } \\
\text { and evaluation. }\end{array}$ \\
\hline $\begin{array}{l}\text { Biggs, H., Clifford-Holmes, } \\
\text { J., Conde-Aller, L., } \\
\text { Lunderstedt, K., Mtati, N., } \\
\text { Palmer, T., Powell, M., } \\
\text { Rosenberg, E.,Rowntree, } \\
\text { K., Van Der Waal, B. and } \\
\text { Wolff, M. }\end{array}$ & 2019 & $\begin{array}{l}\text { The Tsitsa Project Research } \\
\text { Investment Strategy (vol 2) } \\
\text { expanding into praxis: a resource } \\
\text { library (Vol. 2). }\end{array}$ & $\begin{array}{l}\text { Presents a revised set of coherent } \\
\text { praxis-related objectives, Trans-disciplinary } \\
\text { 'stitching together' or unifying activity } \\
\text { between the Tsitsa Project's communities of } \\
\text { practice, whose coordinators were key } \\
\text { authors of parts of the report. Includes a } \\
\text { number of relevant appendices from other } \\
\text { TP processes and meetings. }\end{array}$ \\
\hline
\end{tabular}


Table A1. Cont.

\begin{tabular}{|c|c|c|}
\hline Author(s) & Date & Title \\
\hline $\begin{array}{l}\text { Fabricious, C., Biggs, H. C. } \\
\text { and Powell, M. }\end{array}$ & 2016 & $\begin{array}{l}\text { Research Investment Strategy: } \\
\text { Ntabelanga and Laleni Ecological } \\
\text { Infrastructure Project. }\end{array}$ \\
\hline Herd-Hoare, S. & 2015 & $\begin{array}{l}\text { Understanding local institutions } \\
\text { as a basis for ecological } \\
\text { restoration efforts in communal } \\
\text { areas: the case of Sinxaku Village, } \\
\text { Eastern Cape. }\end{array}$ \\
\hline Hodgson, D. & 2016 & $\begin{array}{l}\text { Demographic Change in the } \\
\text { Upper Tsitsa Catchment: The } \\
\text { Integration of Census and Remote } \\
\text { Sensed Data for } 2001 \text { and } 2011\end{array}$ \\
\hline
\end{tabular}

Huchzermeyer, N.

Huchzermeyer, N.,

Schlegel, P., and van der

Waal, B.

Rowntree, K., Conde-Aller, L., Fox, H., Duma, M., and Ntshudu, M.

Schlegel, P., and

Huchzermeyer, N.

van der Waal, B.,

Rowntree, K., Le Roux, J.,

Buckle, J., Biggs, H.,

Braack, M., Kawa, M.,

Wolff, M., Palmer, T.,

Sisitka, L., Powell, M.,

Clark, R., Ntshudu, M.,

Mtati, N., van Tol, J., and

van Zijl, G.
A baseline survey of channel geomorphology with particular reference to the effects of sediment characteristics on ecosystem health in the Tsitsa River, Eastern Cape, South Africa. Biophysical Monitoring Methods in the Upper Tsitsa River Catchment (T35 A-E).

2018 Improving socio-economic conditions through landscape greening, a case study from the Tsitsa River catchment, uMzimvubu basin. Vol 1 of The Green Village Project-Improving socio-economic conditions of the Tsitsa River catchment and Okhombe communities through landscape greening and integrated green innovations. Biophysical Monitoring Plan Tsitsa River T35A-E, Methodological Outline Report.

The Tsitsa Project Restoration and Sustainable Land Management Plan Infrastructure for Improved Livelihoods and Futures T35A-E (Phase 1 of TP).
Type \& Relevance of Document

Internal TP report, initial research investment strategy for what developed later into the Tsitsa Project.

Honours dissertation focusing on the underlying social causes of land degradation in the TRC.

MSc dissertation, provides demographic profile using South Africa National Population Censuses for 2001 and 2011 and the National Land Cover (NLC) data sets for 2000 and 2013/14

MSc dissertation of the effects of sediment characteristics on ecosystem health in the TRC.

Internal TP report that outlines results from 8 Veld Condition Monitoring sites across T35 A, D \& E. Also outlines rangeland performance and forage production. Water Research Commission Report TT $777 / 1 / 18$, the Green Village Project took a participatory action research approach to identify drivers of poverty, and opportunities to improve socio-economic conditions of communities through landscape greening.

Internal TP report, outlines location, geology, soils, topography, rainfall, vegetation, land use \& land cover (Maps and data of Land cover (1990, 2001 \& 2013/2014-DEA EGIS). Introduces $\mathrm{DPSCR}_{4}$ as the integrated monitoring framework for the Tsitsa Project TP Report to: Department of Environmental Affairs: NRM Programmes.

Directorate-Operational Support and Planning.

\section{Appendix B}

The description of the causal loop diagram (CLD) below focusses on the reinforcing and balancing feedback loops that were omitted from the paper in favor of simpler systems diagrams (Figures 5 and 6) using a format that is more appropriate for the DPSCR 4 LDN framework. See the narrative around Figures 5 and 6 in the paper for a fuller description of the systemic hypothesis of drivers of degradation in the Tsitsa River Catchment.

R1 historical policies driving poverty and disempowerment 
Prior to 1994, apartheid policies forced large numbers of indigenous people on to the Transkei (current communal lands of the catchment), and restricted access to education. These policies fuelled a reinforcing cycle of poverty and disempowerment of the population in the communal lands (R1).

R2 field abandonment driving degradation

During the post-1994 democratic era, freedom of movement has enabled widespread migration decreasing the population of the communal lands as people move in search of opportunities and access to education, thus contributing to the disuse of fields. With increasing disuse of fields, the number of invasive alien plants growing on fields increases, contributing to land degradation, which reduces the viability of agriculture thus leading to further disuse of fields in a reinforcing cycle (R2). Increasing disuse of fields together with a lack of grazing and fire controls leads to grazing on abandoned fields which reduces ground cover on the fields which, combined with the physical characteristics and heavy rainfall lead to soil erosion, sheet erosion, surface runoff and gully formation contributing to land degradation and joining reinforcing cycle (R2) to reduce the viability of agriculture and lead to further disuse of fields.

R3 poverty driving poor stock quality

Poverty decreases the livestock inputs that people can afford, thus drives poor stock quality (health) which reduces livestock products, livestock sale opportunities and livestock value as an asset thus more deeply entrenching poverty in a reinforcing cycle (R3).

R4 poverty driving field abandonment

Poverty decreases people's ability to buy farming inputs which decreases the viability of agriculture, thus increasing the disuse of fields, increasing grazing on abandoned fields which decreases ground cover, further damaging stock quality, which negatively impacts livestock products, livestock sale opportunities and livestock value as an asset, thus more deeply entrenching poverty in a reinforcing cycle (R4).

R5 poverty affecting participation in natural resource (NR) governance

Poverty negatives affects participation in NR governance (it is a barrier to people being able to attend meetings due to transport costs etc.), which is a NR governance factor necessary for natural resource governance. Poor natural resource governance results in a lack of rangeland management with no grazing and fire controls, which reinforces poverty and a lack of participation in NR governance through livestock and field abandonment pathways (R5). Poor natural resource governance as a consequence of the breakdown of local governance systems and other broader national drivers has resulted in poor rangeland management without grazing and fire controls such as rotational grazing. This means that stocking numbers are only controlled through balancing loops B1 and B2.

B1 Food cover and diversity balancing livestock numbers

Traditional values emphasize livestock stocking numbers (with less focus on their productivity) (van der Waal et al., 2018). As stocking numbers go up and continuous grazing takes place, ground cover and graminoid and non-graminoid diversity go down, thus impacting negatively on stock quality (health) leading to livestock deaths which reduces stocking numbers in a balancing loop (B1).

B2 land degradation balancing livestock numbers

Land degradation reduces the livestock carrying capacity of the area, resulting in increased livestock deaths which decreases stocking numbers, thus allowing the landscape to recover and reducing land degradation in a balancing loop (B2). 


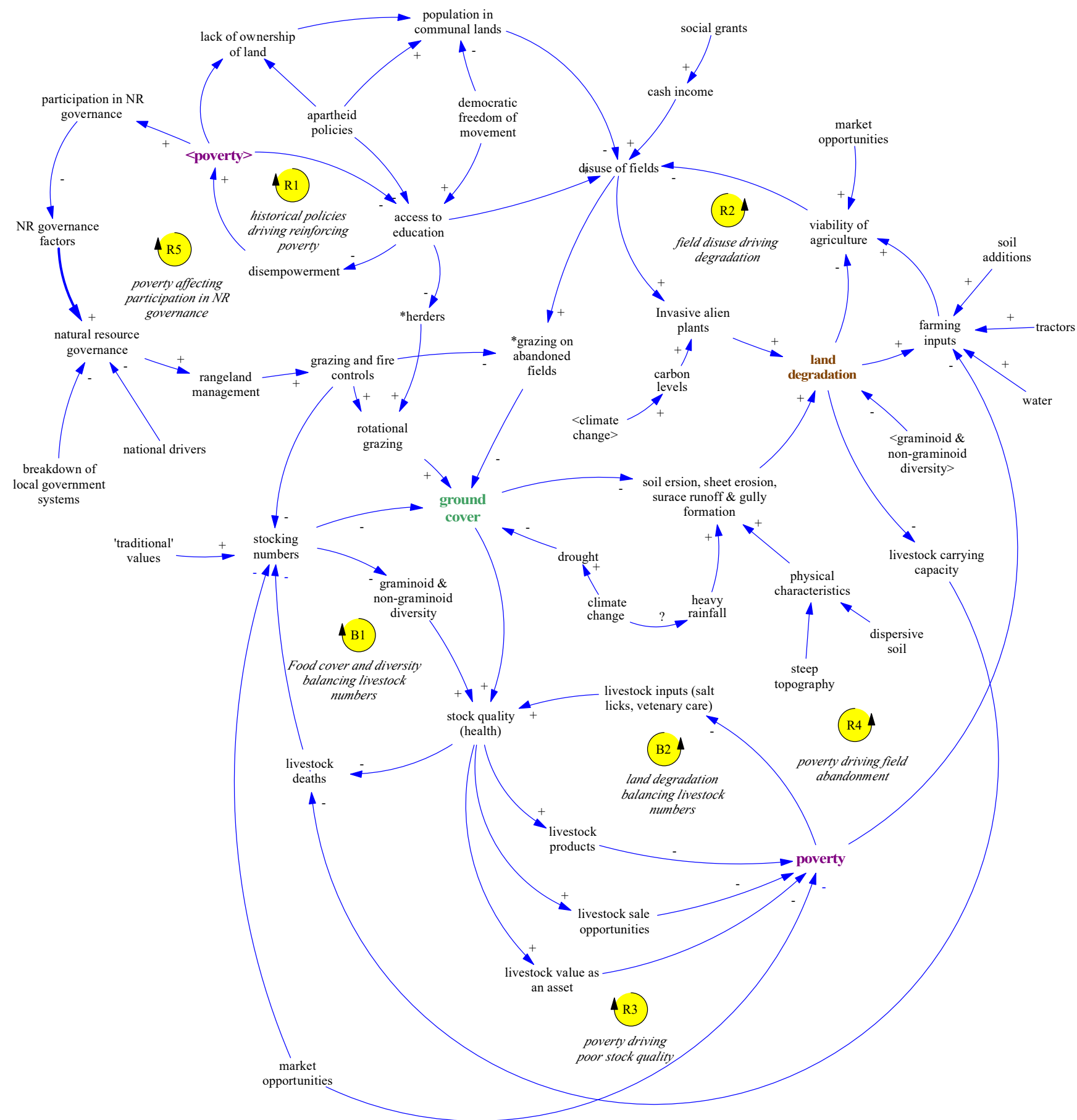

Figure A1. The interview and workshop data as well as a literature and document review were used to draw up a causal loop diagram (CLD) of the linked social-ecological systems (SES) drivers of land degradation in the Tsitsa River Catchment (TRC). The CLD numerically identifies reinforcing loops ' $\mathrm{R}$ ' and balancing feedback loops ' $\mathrm{B}$ ' (highlighted in yellow).

\section{References}

1. Herrero-Jáuregui, C.; Arnaiz-Schmitz, C.; Reyes, M.F.; Telesnicki, M.; Agramonte, I.; Easdale, M.H.; Schmitz, M.F.; Aguiar, M.; Gómez-Sal, A.; Montes, C. What Do We Talk about When We Talk about Social-Ecological Systems? A Literature Review. Sustainability 2018, 10, 2950. [CrossRef]

2. Preiser, R.; Biggs, R.; De Vos, A.; Folke, C. Social-Ecological Systems as Complex Adaptive Systems: Organizing Principles for Advancing Research Methods and Approaches. Ecol. Soc. 2018, 23. [CrossRef] 
3. Hoffman, M.T.; Todd, S. Journal of Southern African A National Review of Land Degradation in South Africa: The Influence of Biophysical and Socio-Economic Factors A National Review of Land Degradation in South Africa: The In Uence of Biophysical and Socio-Economic Factors. J. S. Afr. Stud. 2000, 26, 37-41. [CrossRef]

4. Food and Agriculture Organization of the United Nations (FAO). Land Degradation Assessment in Drylands Methodology and Results LADA Project; FAO: Rome, Italy, 2013.

5. Orr, B.J.; Cowie, A.L.; Castillo Sanchez, V.M.; Chasek, P.; Crossman, N.D.; Erlewein, A.; Louwagie, G.; Maron, M.; Metternicht, G.I.; Minelli, S.; et al. Scientific Conceptual Framework for Land Degradation Neutrality. A Report of the Science-Policy Interface; United Nations Convention to Combat Desertification (UNCCD): Bonn, Germany, 2017.

6. United Nations Environmental Programme (UNEP). GOAL 15: Life on Land I UNEP-UN Environment Programme. Available online: https: / / www.unenvironment.org/explore-topics/sustainable-development-goals/why-do-sustainable-developmentgoals-matter/goal-15 (accessed on 28 December 2020).

7. Cowie, A.L.; Orr, B.J.; Sanchez, V.M.C.; Chasek, P.; Crossman, N.D.; Erlewein, A.; Louwagie, G.; Maron, M.; Metternicht, G.I.; Minelli, S.; et al. Land in Balance: The Scientific Conceptual Framework for Land Degradation Neutrality. Environ. Sci. Policy 2018, 79, 25-35. [CrossRef]

8. United Nations Environmental Programme (UNEP); Food and Agriculture Organization of the United Nations (FAO). The UN Decade on Ecosystem Restoration 2021-2030. UNEP/FAO Factsheet June 2020. Available online: https://wedocs.unep.org/ bitstream/handle/20.500.11822/30919/UNDecade.pdf (accessed on 2 November 2020).

9. Scholes, R.J.; Biggs, R. Ecosystem Services in Southern Africa: A Regional Assessment; The Regional-Scale Component of the Southern African Millennium Ecosystem Assessment; Council for Scientific and Industrial Research: Pretoria, South Africa, 2004.

10. Le Roux, J.J.; Morgenthal, T.L.; Malherbe, J.; Pretorius, D.J.; Sumner, P.D. Water Erosion Prediction at a National Scale for South Africa. Water SA 2008, 34, 305-314. [CrossRef]

11. Sigwela, A.; Elbakidze, M.; Powell, M.; Angelstam, P. Defining Core Areas of Ecological Infrastructure to Secure Rural Livelihoods in South Africa. Ecosyst. Serv. 2017, 27, 272-280. [CrossRef]

12. Dominati, E.; Patterson, M.; Mackay, A. A Framework for Classifying and Quantifying the Natural Capital and Ecosystem Services of Soils. Ecol. Econ. 2010, 69, 1858-1868. [CrossRef]

13. Le Roux, J.; Van Der Waal, B. Gully Erosion Susceptibility Modelling to Support Avoided Degradation Planning. S. Afr. Geogr. J. 2020, 102, 406-420. [CrossRef]

14. Bodin, O.; Alexander, S.M.; Baggio, J.; Barnes, M.L.; Berardo, R.; Cumming, G.S.; Dee, L.E.; Fischer, A.P.; Fischer, M.; Garcia, M.M.; et al. Improving Network Approaches to the Study of Complex Social-Ecological Interdependencies. Nat. Sustain. 2019, 2, 551-559. [CrossRef]

15. Meadows, M.E.; Hoffman, M.T. The Nature, Extent and Causes of Land Degradation in South Africa: Legacy of the Past, Lessons for the Future? Area 2002, 34, 428-437. [CrossRef]

16. Rowntree, K.; Conde-Aller, L.; Fox, H.; Duma, M. Improving Socio-Economic Conditions through Landscape Greening, a Case Study from the Tsitsa River Catchment, UMzimvubu Basin; Vol 1 of The Green Village Project-Improving Socio-Economic Conditions of the Tsitsa River Catchment and Okhombe Communities through landscape greening and integrated green innovations; Water Research Commision: Pretoria, South Africa, 2018.

17. Fabricious, C.; Biggs, H.C.; Powell, M. Research Investment Strategy: Ntabelanga and Laleni Ecological Infrastructure Project. Dep. Environ. Aff. 2016, 24. [CrossRef]

18. Bannatyne, L.J.; Rowntree, K.M.; van der Waal, B.W.; Nyamela, N. Design and Implementation of a Citizen Technician-Based Suspended Sediment Monitoring Network: Lessons from the Tsitsa River Catchment, South Africa. Water SA 2017, 43, 365-377. [CrossRef]

19. Botha, L.; Rosenberg, E.; Biggs, H.; Kotschy, K.; Conde-Aller, L. Ntabelanga-Lalini Ecological Infrastructure Project (NLEIP) Participatory Monitoring, Evaluation, Reflection E Learning (PMERL) Framework; Tsitsa Project Internal Report; Rhodes University: Makhanda, South Africa, 2017.

20. Arnold, R.D.; Wade, J.P. A Definition of Systems Thinking: A Systems Approach. Procedia Comput. Sci. 2015, 44, 669-678. [CrossRef]

21. Van Tol, J.; Akpan, W.; Kanuka, G.; Ngesi, S.; Lange, D. Soil Erosion and Dam Dividends: Science Facts and Rural Fiction around the Ntabelanga Dam, Eastern Cape, South Africa. S. Afr. Geogr. J. 2014, 98, 169-181. [CrossRef]

22. Huchzermeyer, N. A Baseline Survey of Channel Geomorphology with Particular Reference to the Effects of Sediment Characteristics on Ecosystem Health in the Tsitsa River, Eastern Cape, South Africa. Master's Thesis, Rhodes University, Makhanda, South Africa, 2017.

23. Du Plessis, C.; Van Zijl, G.; Van Tol, J.; Manyevere, A. Machine Learning Digital Soil Mapping to Inform Gully Erosion Mitigation Measures in the Eastern Cape, South Africa. Geoderma 2020, 368, 114287. [CrossRef]

24. Schlegel, P.; Huchzermeyer, N. Biophysical Monitoring Plan, Tsitsa River T35 A-E Methodological Outline Report; Tsista Project Internal Report; Rhodes University: Makhanda, South Africa, 2018.

25. Van Der Waal, B.; Rowntree, K.; Roux, J.; Buckle, J.; Biggs, H.; Braack, M.; Kawa, M.; Wolff, M.; Palmer, T.; Sisitka, L.; et al. This Tsitsa Project Restoration and Sustainable Land Management Plan Infrastructure for Improved Livelihoods and Futures T35A-E ( Phase 1 of TP ); Tsista Project Internal Report; Rhodes University: Makhanda, South Africa, 2018. 
26. Biggs, H.; Clifford-holmes, J.; Conde-aller, L.; Lunderstedt, K.; Mtati, N.; Palmer, T.; Powell, M.; Rosenberg, E.; Rowntree, K.; Van Der Waal, B.; et al. The Tsitsa Project Research Investment Strategy (Vol 2) Expanding into Praxis: A Resource Library; Tsista Project Internal Report; Rhodes University: Makhanda, South Africa, 2019.

27. Huchzermeyer, N.; Schlegel, P.; van der Waal, B. Biophysical Monitoring: Report 1 of the Upper Tsitsa River Catchment (T35 a-E) Tsitsa; Tsista Project Internal Report; Rhodes University: Makhanda, South Africa, 2019.

28. Cockburn, J.; Human, H.; Kotschy, K.; Rosenberg, E.; Wolff, M.; Biggs, H. Meta-Reflection Report $2019-2020$ (Final); Tsista Project Internal Report; Rhodes University: Makhanda, South Africa, 2020.

29. Harwell, M.A.; Gentile, J.H.; McKinney, L.D.; Tunnell, J.W.; Dennison, W.C.; Kelsey, R.H.; Stanzel, K.M.; Stunz, G.W.; Withers, K.; Tunnell, J. Conceptual Framework for Assessing Ecosystem Health. Integr. Environ. Assess. Manag. 2019, 15, 544-564. [CrossRef] [PubMed]

30. European Environment Agency (EEA). Technical Report No 25 Environmental Indicators: Typology and Overview; EEA: Copenhagen, Denmark, 1999.

31. United Nations Environmental Programme (UNEP). Global Environment Outlook. GEO 4 Environment for Development. United Nations Environment Programme; UNEP: Nairobi, Kenya, 2007.

32. Masó, J.; Serral, I.; Domingo-Marimon, C.; Zabala, A. Earth Observations for Sustainable Development Goals Monitoring Based on Essential Variables and Driver-Pressure-State-Impact-Response Indicators. Int. J. Digit. Earth 2019, 1-19. [CrossRef]

33. Zaldívar, J.; Cardoso, A.C.; Viaroli, P.; De Wit, R.; Ibañez, C.; Reizopoulou, S.; Razinkovas, A.; Basset, A.; Holmer, M.; Murray, N Eutrophication in Transitional Waters: An Overview. TWM Transit. Waters Monogr. 2008, 1, 1-78. [CrossRef]

34. Payne, G.; Payne, J. Key Informants. In Sage Key Concepts: Key Concepts in Social Research; Payne, G., Payne, J., Eds.; SAGE Publications, Ltd: London, UK, 2004. [CrossRef]

35. Saaty, T.L. Decision Making with the Analytic Hierarchy Process. Int. J. Serv. Sci. 2008, 1, 83-98. [CrossRef]

36. Parwada, C.; Van Tol, J. The Nature of Soil Erosion and Possible Conservation Strategies in Ntabelanga Area, Eastern Cape Province, South Africa. Acta Agric. Scand. Sect. B Soil Plant Sci. 2016, 66, 544-552. [CrossRef]

37. Hebinck, P.; Mtati, N.; Shackleton, C. More than Just Fields: Reframing Deagrarianisation in Landscapes and Livelihoods. J. Rural Stud. 2018, 61, 323-334. [CrossRef]

38. Matsika, R.; Erasmus, B.F.N.; Twine, W.C. A Tale of Two Villages: Assessing the Dynamics of Fuelwood Supply in Communal Landscapes in South Africa. Environ. Conserv. 2013, 40, 71-83. [CrossRef]

39. Shackleton, C.M.; Mograbi, P.J.; Drimie, S.; Fay, D.; Hebinck, P.; Hoffman, M.T.; Maciejewski, K.; Twine, W. Deactivation of Field Cultivation in Communal Areas of South Africa: Patterns, Drivers and Socio-Economic and Ecological Consequences. Land Use Policy 2019, 82, 686-699. [CrossRef]

40. Elsawah, S.; Pierce, S.A.; Hamilton, S.H.; van Delden, H.; Haase, D.; Elmahdi, A.; Jakeman, A.J. An Overview of the System Dynamics Process for Integrated Modelling of Socio-Ecological Systems: Lessons on Good Modelling Practice from Five Case Studies. Environ. Model. Softw. 2017, 93, 127-145. [CrossRef]

41. Forrester, J.W. Information Sources for Modeling the National Economy. J. Am. Stat. Assoc. 1980, 75, 555-566. [CrossRef]

42. Cox, J.; Pitman, A. Catchment Scale Water and Soil Balance Modelling in Southern Australia. In Proceedings of the 12th ISCO Conference, Beijing, China, 26-31 May 2002; pp. 1-8.

43. Davenport, D.; Hughes, B.; Davies, S.; Hall, D. Spread, Delve, Invert: A Best Practice Guide to the Addition of Clay Sandy Soils; Grains Research and Development Corporation (GRDC): Canberra, Australia, 2011.

44. Kakembo, V.; Rowntree, K.M. The Relationship between Land Use and Soil Erosion in the Communal Lands near Peddie Town, Eastern Cape, South Africa. Land Degrad. Dev. 2003, 14, 39-49. [CrossRef]

45. Kusangaya, S.; Warburton, M.L.; van Garderen, E.A.; Jewitt, G.P.W. Impacts of Climate Change on Water Resources in Southern Africa: A Review. Phys. Chem. Earth 2014, 67-69, 47-54. [CrossRef]

46. Drewett, J. Rainfall Variability and Implications for the Tsitsa Catchment, Eastern Cape, South Africa. Honour's Thesis, Rhodes University, Makhanda, South Africa, 2015.

47. Huchzermeyer, N.; Schlegel, P.; van der Waal, B. Biophysical Monitoring Methods in the Upper Tsitsa River Catchment (T35 a-E) Tsitsa; Tsista Project Internal Report; Rhodes University: Makhanda, South Africa, 2019.

48. Fox, R.C. Agriculture and Rural Development. In Geography of South Africa in a Changing World; Fox, R.C., Rowntree, K.M., Eds.; Oxford University Press: Cape Town, South Africa, 2000; pp. 211-232.

49. Hodgson, D.L.; Fox, R.C. Demographic Change in the Upper Tsitsa Catchment: The Integration of Census and Land Cover Data for 2001 and 2011. Master's Thesis, Rhodes University, Makhanda, South Africa, 2017.

50. Mysterud, A. The Concept of Overgrazing and Its Role in Management of Large Herbivores. Wildife Biol. 2006, 12, 129-141. [CrossRef]

51. Du Toit, P.V. The Stocking Rate: Grazing Capacity Relation. Available online: http://gadi.agric.za/articles/duToit_PCV/stockingrate.php (accessed on 30 November 2020).

52. Department of Agriculture, Forestry and Fisheries (DAFF). General Notice on New Long-term Grazing Capacity Map for South Africa 2017; DAFF: Pretoria, South Africa, 2018.

53. Biotrack SA Pty Ltd. Analysis of Long-Term Rangeland Performance and Productivity at Five Sites in the Tsitsa T 35 A, B, C, D and E Quaternary Catchments, and Calculation of Livestock Grazing Capacities; Biotrack SA Pty Ltd: Makhanda, South Africa, 2019. 
54. Herd-Hoare, S. Understanding Local Institutions as a Basis for Ecological Restoration Efforts in Communal Areas: The Case of Sinxaku Village, Eastern Cape. Honour's Thesis, Rhodes University, Makhanda, South Africa, 2015.

55. IPCC. Climate Change and Land: An IPCC Special Report on Climate Change, Desertification, Land Degradation, Sustainable Land Management, Food Security, and Greenhouse Gas Fluxes in Terrestrial Ecosystems; Shukla, P.R., Skea, J., Buendia, E.C., MassonDelmotte, V., Pörtner, H.-O., Roberts, D.C., Zhai, P., Slade, R., Connors, S., van Diemen, R., et al., Eds.; IPCC: Geneva, Switzerland, 2019; in press.

56. DTIC. Masterplan for the Commercial Forestry Sector in South Africa: 2020-2025. Led by DTIC, Prepared by Strategy Execution Advisers (Pty) Ltd, and submitted to DEFF. Available online: https://www.forestrysouthafrica.co.za/wp-content/uploads/2020 /10/Forestry-Masterplan_FINAL.pdf (accessed on 4 December 2020).

57. Aggrey, N.; Wambugu, S.; Karugia, J.; Wanga, E. An Investigation of the Poverty-Environmental Degradation Nexus: A Case Study of Katonga Basin in Uganda. Res. J. Environ. Earth Sci. 2010, 2, 82-88.

58. Kassa, G.; Teferi, B.; Delelegn, N. The Poverty-Environment Nexus in Developing Countries: Evidence from Ethiopia: A Systematic Review. Asian J. Agric. Ext. Econ. Sociol. 2018, 24,1-13. [CrossRef]

59. Ramatshimbila, T.V. Assessing the Poverty-Environment Nexus in Three Rural South African Villages: Environmental Degradation, Vulnerability and Perceptions. Ph.D. Thesis, University of the Witwatersrand, Johannesburg, South Africa, 2018.

60. Uitto, J.I. The Environment-Poverty Nexus in Evaluation: Implications for the Sustainable Development Goals. Glob. Policy 2016, 7, 441-447. [CrossRef]

61. Rowntree, K.; Duma, M.; Kakembo, V.; Thornes, J. Debunking the Myth of Overgrazing and Soil Erosion. L. Degrad. Dev. 2004, 15, 203-214. [CrossRef]

62. Campbell, B.M.; Gordon, I.J.; Luckert, M.K.; Petheram, L.; Vetter, S. In Search of Optimal Stocking Regimes in Semi-Arid Grazing Lands: One Size Does Not Fit All. Ecol. Econ. 2006, 60, 75-85. [CrossRef]

63. O'Connor, T.G.; Kuyler, P.; Kirkman, K.P.; Corcoran, B. Which Grazing Management Practices Are Most Appropriate for Maintaining Biodiversity in South African Grassland? Afr. J. Range Forage Sci. 2010, 27, 67-76. [CrossRef]

64. Badgery, W.B.; Cranney, P.; Millar, G.D.; Mitchell, D.; Behrend, K. Intensive Rotational Grazing Can Improve Profitability and Environmental Outcomes. In Proceedings of the 27th Annual Conference of The Grassland Society of NSW, Wagga Wagga, Australia, 24-26 July 2012; pp. 85-91.

65. Wessels, K.J.; Prince, S.D.; Malherbe, J.; Small, J.; Frost, P.E.; VanZyl, D. Can Human-Induced Land Degradation Be Distinguished from the Effects of Rainfall Variability? A Case Study in South Africa. J. Arid Environ. 2007, 68, 271-297. [CrossRef]

66. Biggs, R.; Bohensky, E.; Desanker, P.V.; Fabricius, C.; Lynam, T.; Misselhorn, A.A.; Musvoto, C.; Mutale, M.; Reyers, B.; Scholes, R.J.; et al. Nature Supporting People: The Southern African Millenium Ecosystem Assessment. Integrated Report; Council of Scientific and Industrial Research: Pretoria, South Africa, 2004.

67. AFR100 (The African Forest Landscape Restoration Initiative). Available online: https:/ / afr100.org (accessed on 16 November 2020).

68. Bond, W.J.; Stevens, N.; Midgley, G.F.; Lehmann, C.E.R. The Trouble with Trees: Afforestation Plans for Africa. Trends Ecol. Evol. 2019, 34, 963-965. [CrossRef]

69. Vetter, S. With Power Comes Responsibility-A Rangelands Perspective on Forest Landscape Restoration. Front. Sustain. Food Syst. 2020, 4, 1-10. [CrossRef] 